\title{
Multilegged Exosomal Walker for Electrochemical Detection of Exosomes
}

Liangliang Wang, ${ }^{\dagger,}$ Yuru Wang, ${ }^{\dagger,}$ Juan Li, ${ }^{\S}$ Lupeng Zeng, ${ }^{\dagger, \ddagger}$ Yijuan Liao, ${ }^{\prime \prime}$ Huifang Mao,

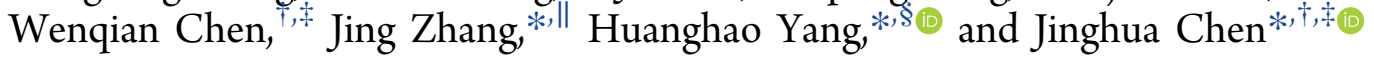

${ }^{\dagger}$ Department of Pharmaceutical Analysis, The School of Pharmacy, Fujian Medical University, Fuzhou, Fujian Province 350122, P. R. China

${ }^{\ddagger}$ Fujian Key Laboratory of Drug Target Discovery and Structural and Functional Research, The School of Pharmacy, Fujian Medical University, Fuzhou, Fujian Province 350122, P. R. China

${ }^{\S}$ MOE Key Laboratory for Analytical Science of Food Safety and Biology, State Key Laboratory of Photocatalysis on Energy and Environment, College of Chemistry, Fuzhou University, Fuzhou, Fujian Province 350108, P. R. China

"Department of Chemical Biology, College of Life Sciences, Fujian Agriculture and Forestry University, Fuzhou, Fujian Province 350002, P. R. China

Supporting Information

ABSTRACT: Detection of exosomes has aroused great interests due to their intrinsic advantages in liquid biopsy for tumor diagnosis and treatment monitoring. Herein, a cascade amplified electrochemical biosensor based on multilegged exosomal walkers was developed for the sensitive and selective detection of exosomes. First, the exosomes were captured specifically by its membrane protein's aptamer and fabricated into multilegged exosomal walkers with a large amount of cholesterol-labeled DNA strands plunging into their lipid bilayers. After being released efficiently by lock nucleic acid (LNA)-modified DNA strands complementary to the aptamers, the walkers were propelled by toehold mediated strand displacement reaction (TMSDR) and "walked" efficiently along DNA "track", introducing considerable signal molecules attached on the "track" and achieving sensitive exosomes detection with a low limit of detection (LOD) of 29 exosomes $/ \mu \mathrm{L}$. Owing to excellent discriminative capability enhanced by LNA and TMSDR, the method possesses high selectivity toward tumor and nontumor

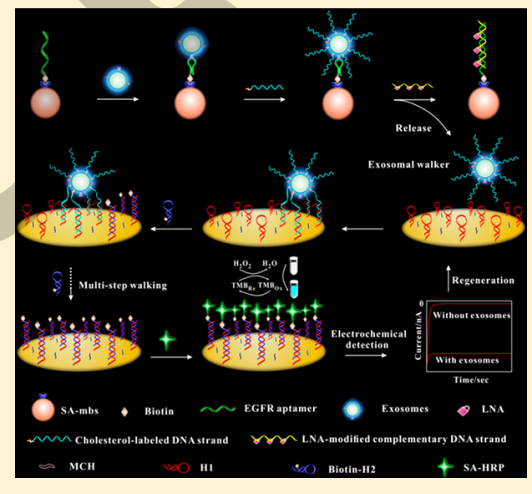
cells derived exosomes, even for the serum exosomes from cancer patients in different stages. Furthermore, the designed biosensor is reproducible. Overall, this approach provides the potential to promote the largescale development of liquid biopsy technology with exosomes as biomarkers.

$\mathrm{E}$ xosomes are a kind of extracellular vesicles secreted by living cells with a diameter of 30-200 nm and lipid bilayer membrane structure. ${ }^{1}$ Exosomes can reflect a variety of information about the microenvironment of tumors and have great applications in accurate diagnosis of tumors. They play a vital role in various physiological and pathological aspects, such as the growth and migration of tumors, the antigen presentation in immunity, etc. ${ }^{1,2}$ Compared with traditional tumor markers such as circulating tumor cells (CTCs), circulating tumor DNA (ctDNA), and circulating free DNA (cfDNA), exosomes are more abundant because they widely exist in blood, saliva, urine, cerebrospinal fluid, breast milk, and other body fluids. ${ }^{3,4}$ Moreover, their unique bilayer structure can effectively protect proteins, RNA, DNA, and other contents from degradation of enzymes. ${ }^{3}$ In brief, exosomes with high abundance and stable structure have huge potentials in real-time tracking of tumors and improving the efficiency of cancer diagnosis. Therefore, a sensitive and specific assay for exosomes is extremely significant.
Recently, many approaches including surface-enhanced Raman spectroscopy (SERS), ${ }^{5}$ surface plasmon resonance (SPR), ${ }^{6}$ microfluidic, ${ }^{7}$ fluorescence, ${ }^{8-11}$ electrogenerated chemiluminescence (ECL), ${ }^{12}$ colorimetric method, ${ }^{13}$ and electrochemistry ${ }^{14-16}$ have been proposed for exosomes detection. In particular, the electrochemical methods exhibit several intrinsic merits, such as easy operation, rapid microanalysis, low cost, high detection sensitivity, miniaturization, and portability. ${ }^{17-19}$ Additionally, to realize highly sensitive detection for exosomes, some signal amplifying methods based on quantum dots, ${ }^{20}$ enzymes, ${ }^{21,22}$ or DNA walkers $^{23}$ have been applied to electrochemistry. It is worth noting that DNA walkers, fueled via nuclease, deoxyribozyme, protease, or light, ${ }^{24,25}$ can "walk" along designed DNA tracks continuously, leading to a cascade signal enhancement. Our group $^{23}$ has proposed a two-footed DNA walker propelled by

Received: August 3, 2019

Accepted: October 25, 2019

Published: October 25, 2019 
Scheme 1. Schematic Principle of the Electrochemical Sensing Based on Multilegged Exosomal Walkers for Exosomes Detection

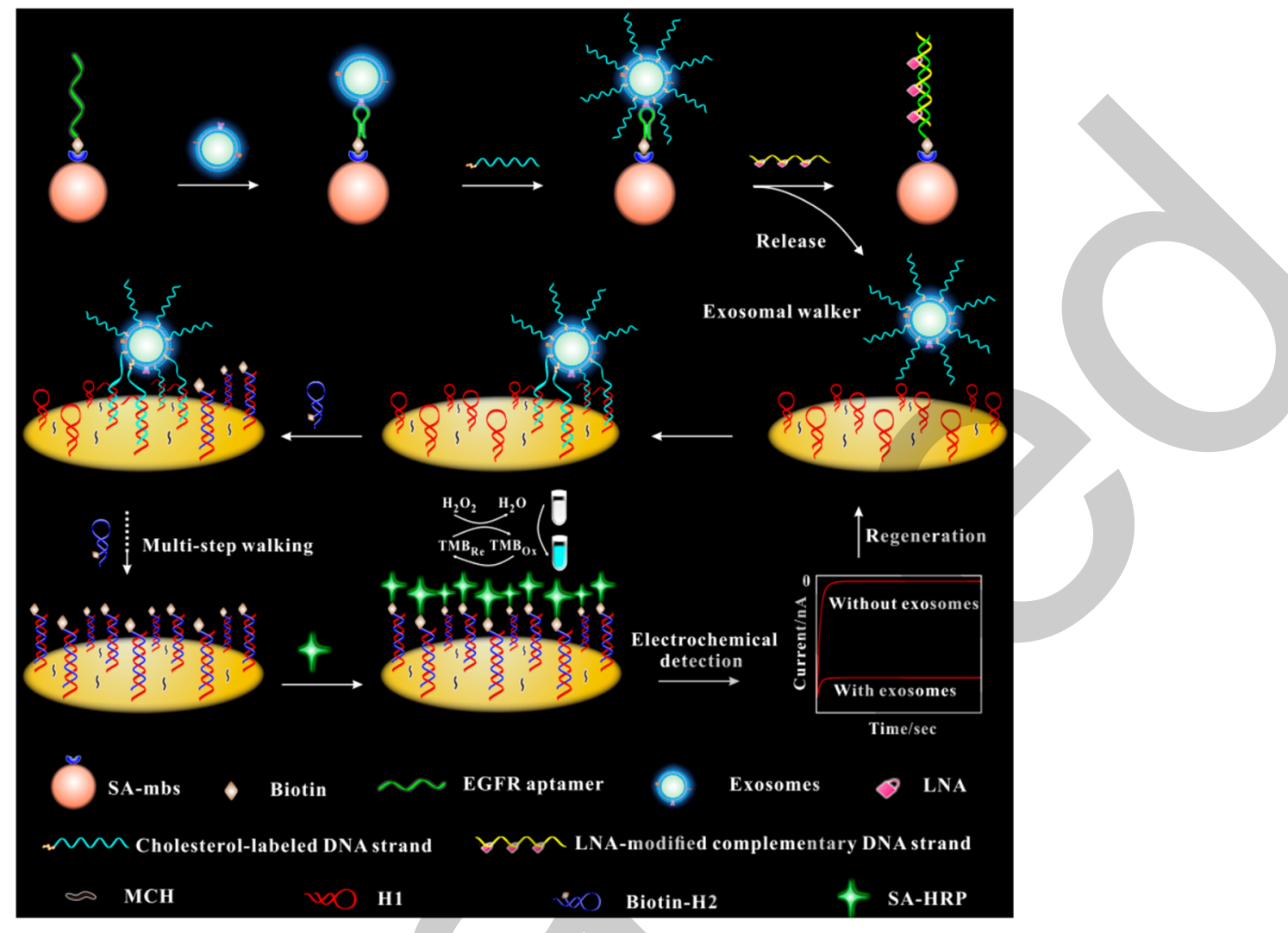

TMSDR for sensitive electrochemical detection of exosomal microRNA. Unlike the burnt bridge principle-based DNA walkers, ${ }^{26,27}$ where DNA tracks are one-off and will be broken into a large number of short DNA segments when DNA walkers go through, our designed walker will not destroy DNA tracks and need no enzyme. Just through simple procedures containing incubation and washing, the DNA tracks can be revived for the next detection. Unfortunately, the developed DNA walker with a linear "body" can only link with two DNA "legs". In the course of walking, the walkers may lift both "legs" at the same time, thus drifting away from DNA tracks. Experimental results showed that the more "legs" the DNA walker has, the more steps and higher rates it can take. ${ }^{28}$

Inspired by these, we try to devise a multilegged DNA walker for exosomes detection. Because "leg" is dependent to a great extent on "body", a suitable "body" is the key point for "multi-legs" design. Up to now, various materials such as streptavidin, micrometer- and nanometer-sized spherical particles had been reported as "body" to fabricate multipedal DNA walker. ${ }^{28-31}$ However, the linkage of DNA "legs" on these particles needs tedious chemical modification. Noteworthily, nanosphere-like exosomes possess a hydrophobic lipid bilayer, which could be easily modified with cholesterol molecules by hydrophobic interaction. ${ }^{32-34}$ Based on all above researches, we plan to take exosomes as "body" to anchor numerous cholesterol-labeled DNA "legs" for the assembly of multilegged exosomal walkers.

Nevertheless, it is the prerequisite to isolate exosomes for walker fabrication. Nowadays, most of the methods for exosomes separation are based on the differences of their physical characteristics and the specific recognition of antigen and antibody. The former includes ultracentrifugation, density gradient centrifugation, ultrafiltration, size exclusion chromatography, etc. ${ }^{4,35}$ However, these methods are cumbersome and time-consuming and lack of selectivity. The latter consists of immunoaffinity assay, microfluidic technology, etc., ${ }^{36,37}$ which significantly improves the specificity of separation by the binding reaction between antibodies and exosomal surface proteins. However, the rigorous reaction conditions and high cost of antibodies make above methods difficult to widely apply. ${ }^{38,39}$ Moreover, the exosomes captured by antibodies are usually released under nonphysiological conditions such as acid, alkali, and high salt, ${ }^{40,41}$ which are inefficient and often bring irreversible effects on the characterization and downstream analysis of exosomes.

In view of the shortcomings of antibodies, aptamers have been proposed for capturing exosomes. Aptamers known as "artificial antibodies" are DNA or RNA fragments screened by the system evolution of ligands by exponential enrichment (SELEX) in vitro. ${ }^{42}$ Compared with antibodies, aptamers have the superiorities of low cost, high stability, high selectivity, wide target molecules, and easy modification. ${ }^{43}$ Surprisingly, researchers have successfully filtrated the aptamers against exosomes and its membrane proteins and realized the capture and detection of exosomes. ${ }^{8,9,44,45}$ It is worth mentioning that the exosomes captured by aptamers can be released gently and entirely by complementary sequences of aptamers, ensuring their biological activity. ${ }^{46}$ Nevertheless, more efforts are still needed for better isolation efficiency of exosomes as well as the accuracy of downstream analysis.

To increase the selectivity and sensitivity of exosomes detection, an electrochemical biosensor based on multilegged 
exosomal walkers fueled by TMSDR was proposed here. Meantime, epidermal growth factor receptor (EGFR) highly expressed exosomes up-regulated in breast cancer MDA-MB231 cells $^{47}$ were adopted as models to analyze its properties. As Scheme 1 shows, after captured by its membrane protein's aptamer (EGFR aptamer), the exosomes were assembled into multilegged exosomal walkers by a great deal of cholesterollabeled DNA strands plunging into their lipid bilayers. Subsequently, the walkers were detached from bound aptamers by LNA modified complementary DNA strands. Since LNA can significantly increase thermal stability of duplex, ${ }^{48,49}$ incorporating LNA into the complementary sequence of aptamer would greatly facilitate the walker's release as well as improve the isolation efficiency of exosomes. Afterward, the walkers "walked" steadily along hairpin probe 1 (H1) DNA tracks propelled by TMSDR, bringing about massive biotins attached on the tracks. Upon addition of streptavidin-labeled horseradish peroxidase (SA-HRP), an enormous electrochemical signal occurred, enabling the detection of the exosomes sensitively down to 29 exosomes $/ \mu \mathrm{L}$. Compared with the unipedal or bipedal DNA walkers, which may easily derail, the designed multilegged exosomal walker can persist on the tracks longer and further, resulting in a great signal amplification as well as higher sensitivity. Moreover, this enzyme-free driven walker will not break the DNA tracks into pieces to cause substantial background signal, unlike the enzyme triggered walkers are based on "burnt bridge" principle. Additionally, this method can discriminate different breast cell-derived exosomes and serum samples owing to the enhanced specificity via LNA and TMSDR. Together with the intrinsic electrochemical advantages, this electrochemical biosensor based on multilegged exosomal walkers holds enormous potential application in cancer diagnosis.

\section{EXPERIMENTAL SECTION}

Reagents and Apparatus. All DNA oligonucleotides were synthesized by Takara Biotechnology Co., Ltd. (Dalian, China), and their base sequences were described in Table S1. The concentrations were quantified using optical density at $260 \mathrm{~nm}$ (OD260) based on absorption coefficients. ${ }^{50,51}$ Streptavidin-modified magnetic beads (SA-mbs) were purchased from Invitrogen. Human breast cancer cell lines (MDAMB-231 and MCF-7) and human mammary epithelial cell line (MCF-10A) were purchased from China Center for Type Culture Collection in Shanghai. Fetal bovine serum (FBS), Roswell Park Memorial Institute (RPMI) and penicillinstreptomycin were purchased from Hyclone. All the other chemicals were analytical grade and purchased from Sinopharm Chemical Reagent Co., Ltd. (Shanghai, China). All aqueous solutions were prepared with Milli-Q water (18 $\mathrm{M} \Omega \cdot \mathrm{cm}$ ).

The ultracentrifuge was Beckman Optima Avanti J-301 (Beckman, U.S.A.). The transmission electron microscopy (TEM) images were performed on a Tecnai G2 microscope (FEI, U.S.A.). The dynamic light scattering (DLS) measurements and Zeta potential analyses were carried out by Litesizer 500 (Anton Paar, Austria). The images of proteins were obtained using Bio-Rad electrochemiluminescence detecting system (Bio-Rad, U.S.A.). The fluorescence images were recorded with a Nikon inverted fluorescence microscope and a Nikon confocal scanning system (Nikon C2, Nikon, Japan). The electrochemical analyses were all carried out on CHI660E analyzer (Shanghai Chenhua Instrument Co., Ltd., China).
Cell Culture and Ultracentrifugation. MCF-7 and MDA-MB-231 cells were cultured in RPMI containing $10 \%$ FBS, $1 \%$ penicillin and streptomycin. MCF-10A cells were maintained in Mammary Epithelial Basal Medium (MEBM) supplemented with $100 \mathrm{ng} / \mathrm{mL}$ cholera toxin. All cells were cultured with a humidified atmosphere of $5 \% \mathrm{CO}_{2}$ in $37{ }^{\circ} \mathrm{C}$. Then, various cells $\left(1 \times 10^{8}\right.$ cells $)$ were respectively cultured in medium containing 5\% exosomes-depleted FBS for $48 \mathrm{~h}$ to collect cell culture supernatant for exosomes isolation. For isolation, according to the ultracentrifugation protocol by our group, ${ }^{23}$ the supernatant was respectively centrifuged at $300 \mathrm{~g}$, $2000 \mathrm{~g}$, and $11000 \mathrm{~g}$ to remove cells, proteins, etc. Finally, the supernatant was centrifuged at $110000 \mathrm{~g}$ to obtain exosomes sediments, and then the pellets were rinsed and resuspended with sterile PBS and stored in $-80^{\circ} \mathrm{C}$ for downstream analysis.

Exosomes Isolation by Aptamers and LNA-Modified Complementary Strands. First, $1 \mu \mathrm{M}$ biotinylated EGFR aptamers were incubated with $0.5 \mathrm{mg} / \mathrm{mL} \mathrm{SA-mbs} \mathrm{in} \mathrm{a}$ reaction buffer ( $\mathrm{pH} 7.5$ ) containing $10 \mathrm{mM}$ Tris, $1.0 \mathrm{mM}$ EDTA, $1 \mathrm{M} \mathrm{NaNO}_{3}, 0.01 \%$ Tween-20, and $0.5 \% \mathrm{BSA}$ at $37^{\circ} \mathrm{C}$ for $30 \mathrm{~min}$ to form EGFR aptamers functionalized magnetic beads (EAmbs). After magnetic separation, the EAmbs were resuspended in cells culture supernatant which has been centrifuged at $300 \mathrm{~g}, 2000 \mathrm{~g}$, and $11000 \mathrm{~g}$, to capture exosomes for $30 \mathrm{~min}$ at room temperature. After reaction, the exosomes captured by EAmbs were separated by magnetic field and rinsed three times with PBST (PBS+ 0.01\% Tween-20). Then, $1 \mu \mathrm{M}$ LNA modified complementary DNA strands dissolved in PBS were added to hybridize with EGFR aptamers at room temperature for $40 \mathrm{~min}$, detaching the captured exosomes from aptamers directly. Finally, the supernatant containing released exosomes was collected upon magnetic separation, quantified with standard curve (Figure S1) by ExoELISA-ULTRA CD63 kit, and characterized by TEM, DLS measurement, Western blot (details shown in the experimental methods in the Supporting Information).

Fabrication of Multilegged Exosomal Walkers. First, exosomes were captured on EAmbs surface by specific binding between EGFR and its aptamers. Then, $5 \mu \mathrm{M}$ cholesterollabeled DNA strands were incubated with captured exosomes in $200 \mu \mathrm{L}$ buffer including $5 \mathrm{mM} \mathrm{MgCl} 2,4.5 \mathrm{~g} / \mathrm{L}$ glucose and $0.01 \%$ BSA in Dulbecco's PBS (D-PBS) to form exosomal walkers. The mixed solution was incubated at $4{ }^{\circ} \mathrm{C}$ overnight. ${ }^{52}$ After the formation of exosomal walkers, the exosomal walkers modified SA-mbs were washed with PBST by magnetic separation to remove the unbound DNA strands as much as possible, and resuspended with same volume of buffer. Specifically, after washed with PBST, exosomal walkers modified SA-mbs in a tube were adsorbed to the bottom by a magnet placed under the tube, and the nonincorporated free DNA remained in the supernatant. Then discarding the supernatant and washing the exosomal walkers modified SAmbs again until the supernatant showed no obvious UV absorption at $260 \mathrm{~nm}$. Finally, the multilegged exosomal walkers were released by LNA-modified complementary strands for subsequent electrochemical analyses.

Electrochemical Measurements. The electrochemical methods of cyclic voltammetry (CV), electrochemical impedance spectroscopy (EIS), differential pulse voltammetry (DPV) and chronoamperometry were used to investigate the performance of electrochemical sensing. CV scanning potential range from -0.1 to $+0.8 \mathrm{~V}$, the quiet time of $2 \mathrm{~s}$, scan rate of $0.1 \mathrm{~V} / \mathrm{s}$ and sample interval of $1 \mathrm{mV}$. EIS was measured with 
an initial potential of $210 \mathrm{mV}$, an execution time of $2 \mathrm{~s}$ and an amplitude of $5 \mathrm{mV}$, accompanied by scanning frequency range from $1-100000 \mathrm{~Hz}$ in $5.0 \mathrm{mM} \mathrm{K} \mathrm{K}_{3}\left[\mathrm{Fe}(\mathrm{CN})_{6}\right] / \mathrm{K}_{4}\left[\mathrm{Fe}(\mathrm{CN})_{6}\right]$ (1:1) solution containing $0.1 \mathrm{M} \mathrm{KCl}$ DPV scanning potentials varied from +0.1 to $+0.6 \mathrm{~V}$, and the potential step, pulse amplitude, pulse width, and pulse period were $4 \mathrm{mV}, 50 \mathrm{mV}$, 0.2 , and $0.5 \mathrm{~s}$, respectively. The chronoamperometry was recorded within $100 \mathrm{~s}$ with an initial potential of $150 \mathrm{mV}$ and sample interval of $0.1 \mathrm{~s}$.

A conventional three electrodes system comprising the gold electrode (GE) as working electrode, a platinum wire auxiliary electrode, and an $\mathrm{Ag} / \mathrm{AgCl}(3 \mathrm{M} \mathrm{KCl})$ reference electrode was utilized to perform all electrochemical experiments. First, GE was polished with 0.05 and $0.3 \mu \mathrm{m}$ alumina slurries to acquire mirror surface, and washed with ethanol and Milli-Q water, respectively. After that, GE was electrochemically treated to clean any remaining impurities until the stable state of current curve in $0.5 \mathrm{M} \mathrm{H}_{2} \mathrm{SO}_{4}$ solution was reached. ${ }^{53}$ Then, $2.5 \mu \mathrm{L}$ of $2 \mu \mathrm{M}$ H1 DNA in Tris buffer $(20 \mathrm{mM}$ Tris, $140 \mathrm{mM} \mathrm{NaCl}, 5$ $\mathrm{mM} \mathrm{KCl}, \mathrm{pH} 7.5$ ) was dripped on the precleaned GE surface for $2 \mathrm{~h}$ at room temperature to form $\mathrm{H} 1 / \mathrm{GE}$. After washed with Milli-Q water, H1/GE was dipped in $2 \mathrm{mM}$ 6-Mercapto1-hexanol $(\mathrm{MCH})$ for $1 \mathrm{~h}$ to remove nonspecific adsorption of DNA and rinsed with water. Next, the supernatant containing the released exosomal walkers was dropped on the surface of $\mathrm{MCH} / \mathrm{H} 1 / \mathrm{GE}$ and incubated at $37{ }^{\circ} \mathrm{C}$ for $1 \mathrm{~h}$. Afterward, 2.5 $\mu \mathrm{L}$ of $1 \mu \mathrm{M}$ biotin-labeled hairpin probe 2 (biotin-H2) DNA was spread on the GE surface for $2 \mathrm{~h}$, and then $10 \mu \mathrm{g} / \mathrm{mL}$ SAHRP was added. After rinsed, the well-prepared GE was ultimately transferred for electrochemical measurements.

\section{RESULTS AND DISCUSSION}

Experimental Mechanism of the Electrochemical Detection. As depicted in Scheme 1, exosomes were first separated from cell cultural supernatant by stable binding between EGFR proteins and EAmbs. Subsequently, a large amount of cholesterol-labeled DNA strands penetrated into the exosomal lipid bilayer as "legs", resulting in the formation of multilegged exosomal walkers. Upon addition of LNAmodified complementary DNA strands of aptamers, the exosomal walkers were released entirely and effectively. When they accessed to the H1 DNA tracks-immobilized GE surface, the walkers adhered to the DNA tracks by specific hybridization between legs' sequence and $\mathrm{H} 1$, leaving a new toehold exposed on H1. After the addition of biotin-H2 DNA, $\mathrm{H} 2$ hybridized competitively with $\mathrm{H} 1$ through TMSDR owing to the toehold, propelling the walkers to take the next step. The more steps the walkers took, the more biotins occurred on GE surface. When adding SA-HRP, the electrode generated an enhanced catalytic current in $\mathrm{H}_{2} \mathrm{O}_{2}$ /TMB solution with an apparent color change (from colorless to blue). By recording the current signal, this selective and sensitive detection of exosomes was realized.

Feasibility of the Separation Method Based on Aptamers and Its Complementary Strands. To prove the feasibility of the proposed separation method, the MDAMB-231 cells-derived exosomes separated by EGFR aptamers and its LNA-modified complementary strands were characterized. Initially, the formation of EAmbs used for exosomes capture was characterized by biotin- and Cy3-labeled aptamer (Figure S2A) under inverted fluorescence microscope. As Figure S2B shows, the red spots identified the aptamers were indeed attached on the surface of SA-mbs to form EAmbs.
Then laser confocal fluorescence microscopy was adopted to characterize the exosomes captured by EAmbs. ${ }^{54}$ As expected, after colored by membrane dye DiI, the exosomes captured by EAmbs showed red fluorescence (Figure S3-a) while no evident fluorescence emerged when using SA-mbs to capture exosomes (Figure S3-b), indicating the success of exosomes capture by EAmbs.

Next, the morphology, size, and proteins of the exosomes released by LNA labeled complementary strands were characterized according to the International Society for Extracellular Vesicles (ISEV) guideline. ${ }^{55}$ First, the TEM image showed the cup-shaped exosomes with the diameter range of $90-110 \mathrm{~nm}$ in Figure 1A, which coincides with the

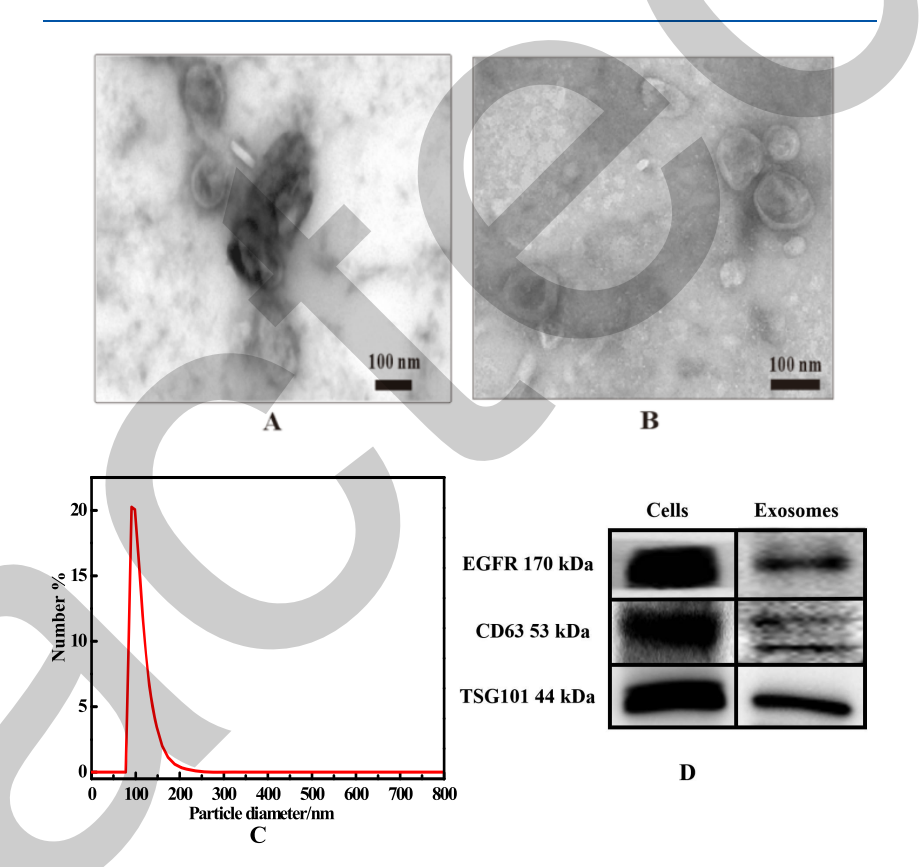

Figure 1. A. TEM image of the exosomes released by LNA labeled complementary strands. B. The TEM image of the exosomes isolated by ultracentrifugation. C. The DLS distribution of exosomes released by our proposed method. D. The Western blot images of membrane proteins of cells and released exosomes.

previous literatures. ${ }^{47}$ In addition, it is worth noting that the TEM image of exosomes separated by this method showed less impurities than that of the exosomes separated by ultracentrifugation (Figure 1B). ${ }^{40,56}$ Second, the exosomes size was further detected by DLS measurement. As shown in Figure 1C, the mean effective diameter of released exosomes was around $113 \pm 3.5 \mathrm{~nm}$ with a polydispersity index (PDI) of 0.18 , which is in accordance with that of the exosomes isolated by ultracentrifugation (Figure S4). The exosomes sizes in DLS measurements were slightly larger than that in TEM results, because the DLS results showed the hydrodynamic diameter of the exosomes in solution while the exosomes captured in TEM images were shrunk in preparation process. ${ }^{47,57}$ Finally, the exosomal membrane proteins were analyzed by Western blot. Figure 1D showed clear immunoreactive bands corresponding to EGFR, CD63, and TSG101 proteins of exosomes, respectively, which were consistent with the parent cells and previous reports. ${ }^{47,58}$ In brief, all of the above results confirmed that the designed isolation method is feasible and may be a potential alternative or further improvement to ultracentrifugation. 
Characterization of Multilegged Exosomal Walkers.

The formation of multilegged exosomal walkers was studied using carboxyfluorescein (FAM)- and cholesterol-labeled DNA "legs" as fluorescence probes. Owing to the composition similarity of lipid bilayer between exosomes and parent cells, ${ }^{34}$ cells equipped with fluorescence probes were first observed. The green fluorescent circles in Figure 2A-a suggested the
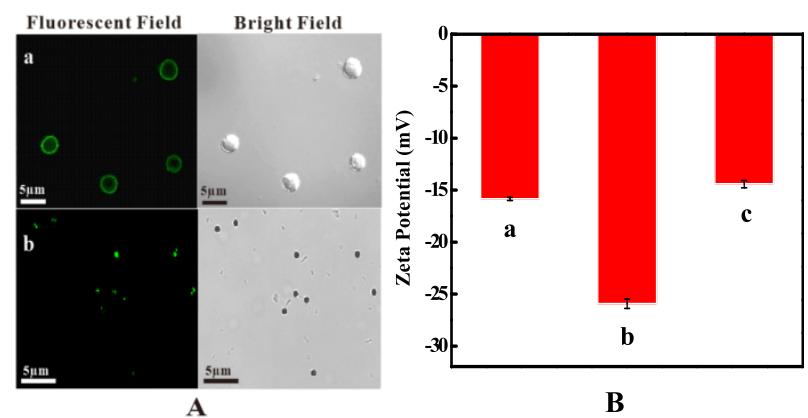

Figure 2. Characterization of multilegged exosomal walkers. A. The laser confocal fluorescence images of MDA-MB-231 cells (a) and EAmbs captured exosomes derived from MDA-MB-231 cells (b) after incubating with FAM and cholesterol-labeled DNA "legs". B. The zeta potential of exosomes before (a) and after (b) incubating with cholesterol-labeled DNA "legs", and further treated with DNase I (c).

cholesterol-modified DNA "legs" can be plunged into lipid bilayer through hydrophobic interaction. Second, the anchoring of cholesterol-labeled DNA "legs" on EAmbs captured exosomes was confirmed by the green fluorescent spots in Figure 2A-b. ${ }^{32,54}$ Subsequently, zeta potential analysis was applied to further verify the formation of multilegged exosomal walkers. ${ }^{52}$ The zeta potentials of exosomes before (Figure 2Ba) and after (Figure 2B-b) equipping with DNA "legs" were -15.84 and $-25.93 \mathrm{mV}$, respectively. The decreased zeta potential suggested the binding of DNA "legs" which possess negatively charged phosphate back-bones. Upon the addition of DNase I, the zeta potential turned to be $-14.41 \mathrm{mV}$ (Figure $2 \mathrm{~B}-\mathrm{c})$, indicating that the DNA "legs" on exosomal membrane were digested by DNase I. In a word, all above results proved the assembly of multilegged exosomal walkers is feasible. Additionally, the exosomal walker released by LNA labeled complementary strands were also characterized by TEM (Figure S5). The intact morphology of exosomes verified the integrity of exosomes after the formation of multilegged exosomal walkers.

Walking Feasibility of Multilegged Exosomal Walkers. First, we examined walking feasibility of multilegged exosomal walkers on ferrocene $(\mathrm{Fc})$-labeled $\mathrm{H} 1$ (Fc-H1) DNA tracks by DPV. Initially, numerous Fc on GE surface generated a large electrochemical signal $\left(\mathrm{I}_{\mathrm{a}}\right)$ (Figure 3A-a and B-a). In the presence of $\mathrm{H} 2$, because of the kinetical trap between $\mathrm{H} 1$ and $\mathrm{H} 2, \mathrm{H} 2$ is unable to hybridize with $\mathrm{H} 1$, resulting in little changed current $\left(I_{b}\right)$ (Figure 3A-b and B-b). When exosomal walkers accessed to DNA tracks, their DNA "legs" would hybridize with $\mathrm{Fc}_{\mathrm{C}} \mathrm{H} 1$, making a small quantity of $\mathrm{Fc}$ molecules far from GE surface and new toehold exposed on $\mathrm{H} 1$, accompanied by a slightly decreased current $\left(I_{c}\right.$; Figure 3A-c and $\mathrm{B}-\mathrm{c}$ ). Then, with the addition of $\mathrm{H} 2$, it displaced the combined DNA "legs" to hybridize with Fc-H1 through TMSDR, propelling the walkers to move toward another $\mathrm{H} 1$ DNA tracks. As a result, a mass of Fc were far from GE surface, inducing conspicuous decrease of the current signal $\left(\mathrm{I}_{d}\right)$

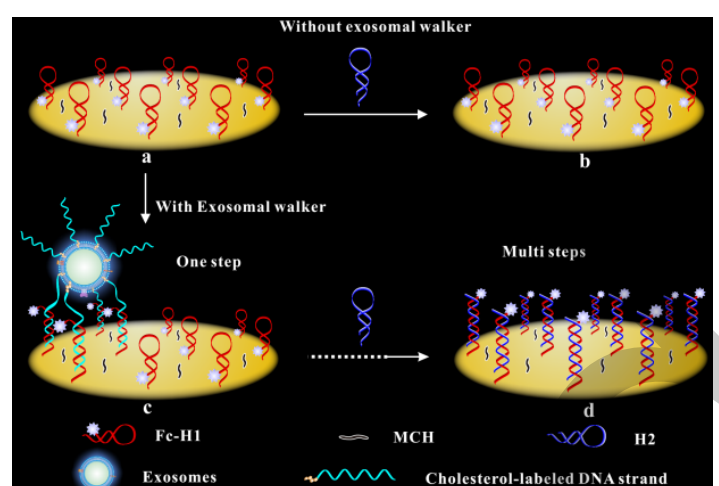

A
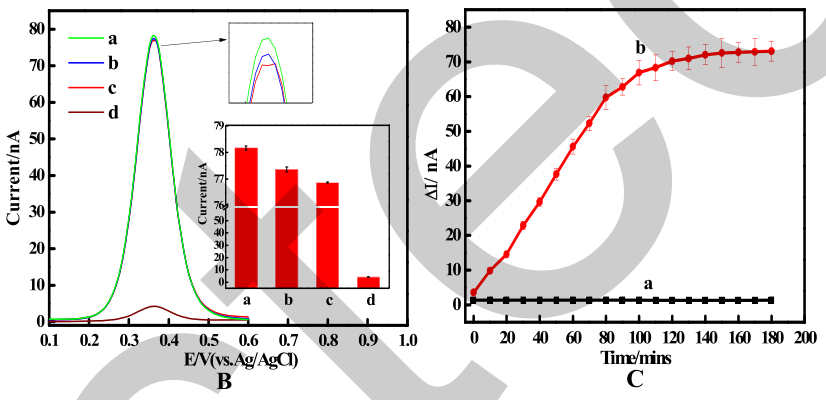

Figure 3. A. Walking process of exosomal walkers on Fc-labeled H1 DNA tracks. B. DPV curves of different GE with Fc-labeled H1 DNA tracks. (a) $\mathrm{MCH} / \mathrm{Fc}-\mathrm{H} 1 / \mathrm{GE}$, (b) $\mathrm{MCH} / \mathrm{Fc}-\mathrm{H} 1 / \mathrm{GE}$ incubated with $\mathrm{H} 2$, and (c) $\mathrm{MCH} / \mathrm{Fc}-\mathrm{H} 1 / \mathrm{GE}$ incubated with exosomal walkers. Upper inset: The enlarged graphs of distinguishing current peaks of different GE. Lower inset: Current histogram of different GE. (d) $\mathrm{MCH} / \mathrm{Fc}-\mathrm{H} 1 / \mathrm{GE}$ incubated with $\mathrm{H} 2$ and exosomal walkers. C. The current changes induced by walking behavior of one step (a) or multisteps (b) on Fc-H1 modified GE.

(Figure 3A-d, Figure 3B-d). Subsequently, CV (Figure S6A) and EIS (Figure S6B) were also measured to monitor walking process of the exosomal walkers, showing consistent results with that of DPV. These findings suggest that the multilegged exosomal walkers can walk with the assistance of TMSDR. Additionally, the exosomal walkers after the walking process were characterized by TEM (Figure S7). The whole exosomes in TEM image also demonstrated the integrity of exosomes and further the walking feasibility of exosomal walkers.

To further verify the feasibility of this walking strategy and quantitatively evaluate walking performance of the multilegged exosomal walkers, we defined one-step and multisteps walking according to the Figure $3 \mathrm{~A}$ and $3 \mathrm{~B}$, respectively. The one-step walking induced current signal $\left(I_{\text {one }}\right)$ is the current change before $\left(I_{\mathrm{a}}\right)$ and after $\left(I_{\mathrm{c}}\right)$ walkers binding to $\mathrm{H} 1\left(I_{\text {one }}=I_{\mathrm{a}}-I_{\mathrm{c}}\right)$. Likewise, the current signal induced by multisteps walking $\left(I_{\text {multi }}\right)$ is $I_{\mathrm{b}}$ minus $I_{\mathrm{d}}\left(I_{\text {multi }}=I_{\mathrm{b}}-I_{\mathrm{d}}\right)$. As Figure 3C shows, $I_{\text {one }}$ (curve a) almost remained unchanged while the $I_{\text {multi }}$ (curve b) increased as time went by and then reached the plateau after $120 \mathrm{~min}$. The largest $I_{\text {multi }}$ is approximately 55 times more than $I_{\text {one }}$ indicating 55 walking steps. Compared with other strand displacement-based DNA walkers (Table S2), ${ }^{59,60}$ exosomal walkers possessing distinctive "body" is easier to equip DNA "legs" with higher efficiency. Furthermore, the exosomal walkers with more "legs" ( 473 molecules/exosome, see Table S2 and Figure S8) would be more stable in tracks, and thus walk more steps.

Optimization of Experimental Conditions. To obtain excellent properties, experimental conditions affecting the 
separation and detection of the exosomes were optimized. First, some important parameters affecting the separation efficiency of exosomes were investigated using the current change before and after exosomes addition. As shown in Figure S9, the maximum current changes were acquired in $0.5 \mathrm{mg} / \mathrm{mL}$ SA-mbs (Figure S9A), $1 \mu \mathrm{M}$ EGFR aptamers (Figure S9B), 30 min capture time (Figure S9C), and $40 \mathrm{~min}$ release time (Figure S9D), respectively.

Additionally, LNA number labeled in complementary strands (Table S3) was studied to increase the isolation efficiency of exosomes as well as exosomal walkers because it can enhance the helical thermostability via increasing the melting temperature of DNA duplex, ${ }^{48,49}$ and further enhance the electrochemical signal. By counting the exosomes number before and after separation process, the isolation efficiency of exosomes drawn in Figure S9E achieve the maximum value at 9 LNA modification, and was calculated with an average value of $89.00 \pm 1.60 \%$ (Table S4), which was higher than that of the separation methods by LNA-free complementary strands $(67.44 \pm 2.88 \%$, Table S4) or ultracentrifugation (around $78 \%) .{ }^{46}$ As shown in Figure S9F, the current change raised with the increase of LNA number, and then reached a plateau when LNA number was 9. Then, the parameters influencing the exosomes detection, such as the concentrations of $\mathrm{H} 1$ DNA (Figure S10A), H2 DNA (Figure S10B), and DNA "legs" (Figure S10C), the walking time (Figure S10D) in the walking process of exosomal walkers, and the concentration of SA-HRP (Figure S10E), were optimized as $2 \mu \mathrm{M}, 1 \mu \mathrm{M}, 5 \mu \mathrm{M}$, $120 \mathrm{~min}$, and $10 \mu \mathrm{g} / \mathrm{mL}$, respectively.

Properties of the Electrochemical Method. Under the optimal conditions, the current-time curves related to different concentrations of MDA-MB-231 cells-derived exosomes were measured to investigate the sensitivity of this method. As presented in Figure 4A, the current intensity
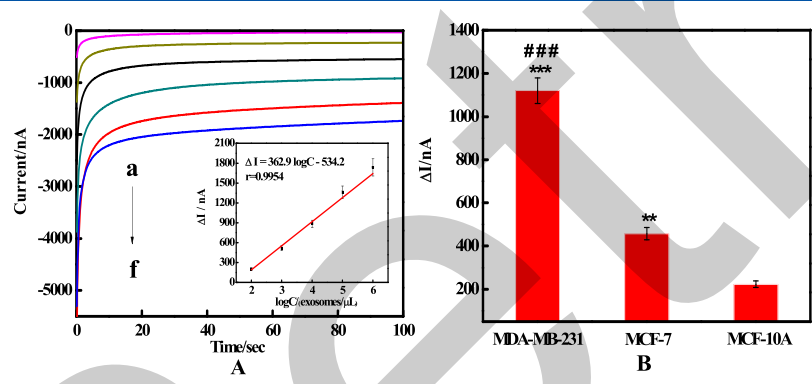

Figure 4. A. The current-time curves of different concentration of exosomes (a-f: $0,10^{2}, 10^{3}, 10^{4}, 10^{5}$, and $10^{6}$ exosomes $/ \mu \mathrm{L}$ ). Inset: The linear regression curves and equations of $\Delta I$ versus logarithm of exosomes concentration $\left(\log \mathrm{C}, \mathrm{C}: 10^{2}, 10^{3}, 10^{4}, 10^{5}\right.$, and $10^{6}$ exosomes $/ \mu \mathrm{L})$. B. The selectivity analysis of exosomal walker-based method. Error bar is based on triplicate experiments. $(* p<0.05$, $* * p$ $<0.01$, *** $p<0.001$ versus MCF-10A cells derived exosomes; \#p < $0.05, \# \# p<0.01, \# \# \# p 0.001$ versus MCF-7 cells derived exosomes; two-tailed $t$ test).

gradually increased with rising of exosomes concentration from 0 to $10^{6}$ exosomes $/ \mu \mathrm{L}$. There was a good linear relation between the current change $(\Delta I)$ before and after exosomes addition and logarithm of exosomes concentration $(\log C)$ in Figure 4A-inset. The regression equation is $\Delta I=362.9 \log \mathrm{C}-$ 534.2 with a correlation coefficient of 0.9954 . The LOD based on $3 \sigma(\sigma=0.03055)$ rule $^{61}$ was calculated to be 29 exosomes/ $\mu \mathrm{L}$ by putting $3 \sigma$ into the regression equation as $\Delta I$ for the determination of $\mathrm{C}$ ( $\mathrm{C}$ was the LOD). As expected, the LOD of this method is far less than those of the commercial kit (ExoELISA-ULTRA CD63 kit) and many recent approaches (Table S5), indicating the excellent sensitivity for exosomes detection. Although some assays based on SPR, ${ }^{6}$ microfluidic, ${ }^{7}$ electrochemistry, ${ }^{16,62}$ etc., exhibited higher sensitivity than our method, those works require either antibodies or enzymesassisted amplification, which may need strict control of reaction conditions and high cost. In our work, the cascade signal amplification of the multilegged exosomal walker was performed in antibody-free and enzyme-free mode, with the advantages of low cost, simple operation, portability, etc.

Next, exosomes derived from metastatic breast cancer (MCF-7 cells) and normal human breast epithelial cells (MCF-10A cells) were chosen to validate the selectivity of this method. Meanwhile, the TEM images and DLS measurements results of MCF-7 cells and MCF-10A cells derived exosomes were shown in Figures S11 and S12, respectively. As depicted in Figure 4B, the induced current signals decreased from MDA-MB-231 cells derived exosomes, MCF-7 cells derived exosomes to MCF-10A cells derived exosomes, which was in a good agreement with the expression level of exosomal membrane protein EGFR reported before. ${ }^{47}$ The above results elucidated that the designed method possesses excellent capability in distinguishing metastatic tumor, nonmetastatic tumor and healthy control.

Moreover, the reproducibility of this biosensor was analyzed by repeated detection of $10^{4}$ exosomes $/ \mu \mathrm{L}$ for 5 times. As shown in Table S6, the relative standard deviation (RSD) of $5.29 \%$ confirmed good reproducibility of the proposed method. In addition, the DNA tracks of the used biosensor can be regenerated only by incubating in $90{ }^{\circ} \mathrm{C}$ for $5 \mathrm{~min}$ and rinsing with Tris buffer several times. After 5 cycles of the regeneration procedure (Figure S13), the current signal only reduced $9.8 \%$ compared with initial current intensity, exhibiting the good regeneration ability and stability of this electrochemical method.

Detection of Exosomes in Human Serums. To assess the practical applicability of the proposed strategy, serum samples from triple negative breast cancer (TNBC) patients, nontriple negative breast cancer (NTNBC) patients and healthy individuals were analyzed. First, the TNBC-derived serums were collected and classified into stages I (TNBC-I), II (TNBC-II) and III (TNBC-III) according to the staging criteria of tumor node metastasis (TNM) established by American Joint Committee on Cancer (AJCC) and Union for International Cancer Control (UICC). ${ }^{63}$ All the procedures were in accordance with the relevant guidelines and regulations. Subsequently, the serums were diluted with sterile PBS, and then filtrated using $0.22 \mu \mathrm{m}$ filter ${ }^{46}$ for exosomes detection based on the multilegged exosomal walkers. As Figure 5 displayed, the current intensity significantly increased in the order of healthy samples (HS), NTNBC and TNBC (from stage I to III) patients serum, which was corresponding to the expression levels of EGFR proteins. ${ }^{64}$ All results suggested the proposed strategy is capable of recognizing TNBC-, NTNBC- and nontumor derived exosomes, even distinguishing different stages of TNBC in real samples.

\section{CONCLUSION}

In a word, a multilegged exosomal walker was designed for selective and sensitive electrochemical detection of exosomes. First, the multiple legs make the exosomal walker difficult to 


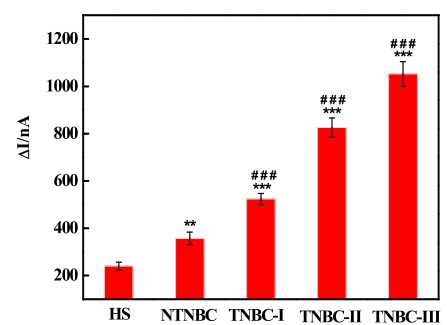

Figure 5. Change values of current signals $(\Delta I)$ before and after the addition of exosomes derived from healthy samples (HS), NTNBC and TNBC (stages I, II, and III) patients serum. Error bar is based on triplicate experiments. $(* p<0.05, * * p<0.01$, and $* * * p<0.001$ versus controls (HS); \#p $<0.05$, \#\#p $<0.01$, and \#\#\#p $<0.001$ versus NTNBC; two-tailed $t$ test).

derail, resulting in higher walking efficiency and assay sensitivity with LOD of 29 exosomes/ $\mu$ L. Furthermore, the plunge of cholesterol into exosomal lipid bilayer simplifies the assembly process of multilegged exosomal walker, along with few exotic reagents and low background signal. Second, LNA modification of complementary strand of aptamer significantly increases the isolation efficiency of exosomes. Finally, the TMSDR, based on "unburned bridge" principle, can propel the walker effectively without the damage of DNA tracks. Therefore, the developed biosensor can be reused just through simple washing and incubation. In the future, multivalent aptamers based on $2 \mathrm{D}$ or $3 \mathrm{D}$ DNA structures ${ }^{65}$ may be introduced into exosomes capture to isolate exosomes with higher yield, purity and specificity. And ratiometric ${ }^{66}$ or multimodal signal readout ${ }^{67}$ methods may be taken into consideration to enhance the stability and accuracy of detection. Additionally, more clinical samples would be collected to test and improve its performance. In brief, together with the intrinsic advantages of electrochemical biosensor such as simple operation, low cost, portability, etc., the proposed approach holds great promise in exosomes based liquid biopsy.

\section{ASSOCIATED CONTENT}

\section{S Supporting Information}

The Supporting Information is available free of charge on the ACS Publications website at DOI: 10.1021/acs.analchem.9b03539.

Partial experimental methods used in this work; the sequences of DNA mentioned in this work; the standard curve for exosomes counting by kit; the characterization of EGFR aptamers functionalized magnetic beads; the fluorescence images of captured exosomes; the DLS measurement of MDA-MB-231 cells derived exosomes isolated by ultracentrifugation; the TEM image of the released exosomal walkers; the feasibility characterization by CV and EIS; the TEM image of the exosomal walkers after the walking process; the standard fluorescence curve of FAM-labeled DNA "legs"; the comparison of walking steps of various DNA walkers based on strand displacement; optimization of experimental parameters for the isolation process; the LNAmodified complementary strands of EGFR DNA aptamer; the isolation efficiency of exosomes; optimization of experimental parameters for the walking process; the comparison of current methods for exosomes detection; TEM images of MCF-7 cells and MCF-10A cells derived exosomes; DLS measurements of MCF-7 cells and MCF-10A cells derived exosomes; the repeated detection of exosomes for 5 times; the current intensity of initial detection and after regeneration (PDF)

\section{AUTHOR INFORMATION}

\section{Corresponding Authors}

*E-mail: cjh_huaxue@126.com.

*E-mail: hhyang@fzu.edu.cn.

*E-mail: 1601225385@qq.com.

ORCID $\odot$

Huanghao Yang: 0000-0001-5894-0909

Jinghua Chen: 0000-0001-8718-0232

\section{Notes}

The authors declare no competing financial interest.

\section{ACKNOWLEDGMENTS}

The authors gratefully acknowledge National Natural Science Foundation of China (No. 21874019), Natural Science Foundation of Fujian Province (No. 2017J07001), Fujian Science and Technology Innovation Joint Found Project (2016Y9050), Startup Fund for Scientific Research, Fujian Medical University (2018QH2015), Young Top-notch Talent Project of Colleges and Universities of Fujian Province (3002360301), and United Fujian Provincial Health and Education Project for Tacking the Key Research P.R. China (WKJ2016-2-30).

\section{REFERENCES}

(1) Zhang, H.; Deng, T.; Liu, R.; Bai, M.; Zhou, L.; Wang, X.; Li, S.; Wang, X.; Yang, H.; Li, J.; Ning, T.; Huang, D.; Li, H.; Zhang, L.; Ying, G.; Ba, Y. Nat. Commun. 2017, 8, 15016.

(2) van Niel, G.; D’Angelo, G.; Raposo, G. Nat. Rev. Mol. Cell Biol. 2018, 19, 213-228.

(3) De Rubis, G.; Rajeev Krishnan, S.; Bebawy, M. Trends Pharmacol. Sci. 2019, 40, 172-186.

(4) Ramirez, M. I.; Amorim, M. G.; Gadelha, C.; Milic, I.; Welsh, J. A.; Freitas, V. M.; Nawaz, M.; Akbar, N.; Couch, Y.; Makin, L.; et al. Nanoscale 2018, 10, 881-906.

(5) Kruglik, S. G.; Royo, F.; Guigner, J. M.; Palomo, L.; Seksek, O.; Turpin, P. Y.; Tatischeff, I.; Falcón-Pérez, J. M. Nanoscale 2019, 11, $1661-1679$.

(6) Wang, Q.; Zou, L.; Yang, X.; Liu, X.; Nie, W.; Zheng, Y.; Cheng, Q.; Wang, K. Biosens. Bioelectron. 2019, 135, 129-136.

(7) Xu, H.; Liao, C.; Zuo, P.; Liu, Z.; Ye, B. C. Anal. Chem. 2018, 90, 13451-13458.

(8) Lyu, Y.; Cui, D.; Huang, J.; Fan, W.; Miao, Y.; Pu, K. Angew. Chem., Int. Ed. 2019, 58, 4983-4987.

(9) He, D.; Ho, S. L.; Chan, H. N.; Wang, H.; Hai, L.; He, X.; Wang, K.; Li, H. W. Anal. Chem. 2019, 91, 2768-2775.

(10) Gao, M. L.; He, F.; Yin, B. C.; Ye, B. C. Analyst 2019, 144, 1995-2002.

(11) Wang, L.; Yang, Y.; Liu, Y.; Ning, L.; Xiang, Y.; Li, G. Chem. Commun. 2019, 55, 2708-2711.

(12) Zhang, H.; Wang, Z.; Zhang, Q.; Wang, F.; Liu, Y. Biosens. Bioelectron. 2019, 124-125, 184-190.

(13) Chen, J.; Xu, Y.; Lu, Y.; Xing, W. Anal. Chem. 2018, 90 14207-14215.

(14) Wang, S.; Zhang, L.; Wan, S.; Cansiz, S.; Cui, C.; Liu, Y.; Cai, R.; Hong, C.; Teng, I. T.; Shi, M.; Wu, Y.; Dong, Y.; Tan, W. ACS Nano 2017, 11, 3943-3949.

(15) Park, J.; Lin, H. Y.; Assaker, J. P.; Jeong, S.; Huang, C. H.; Kurdi, T.; Lee, K.; Fraser, K.; Min, C.; Eskandari, S.; et al. ACS Nano 2017, 11, 11041-11046. 
(16) Boriachek, K.; Masud, M. K.; Palma, C.; Phan, H. P.; Yamauchi, Y.; Hossain, M. S. A.; Nguyen, N. T.; Salomon, C.; Shiddiky, M. J. A. Anal. Chem. 2019, 91, 3827-3834.

(17) Si, Y.; Sun, Z.; Zhang, N.; Qi, W.; Li, S.; Chen, L.; Wang, H. Anal. Chem. 2014, 86, 10406-10414.

(18) Liu, M.; Zhang, L.; Hua, Y.; Feng, L.; Jiang, Y.; Ding, X.; Qi, W.; Wang, H. Anal. Chem. 2017, 89, 9552-9558.

(19) Hua, Y.; Lv, X.; Cai, Y.; Liu, H.; Li, S.; Wan, Y.; Wang, H. Chem. Commun. 2019, 55, 1271-1274.

(20) Boriachek, K.; Islam, M. N.; Gopalan, V.; Lam, A. K.; Nguyen, N. T.; Shiddiky, M. J. A. Analyst 2017, 142, 2211-2219.

(21) Dong, H.; Chen, H.; Jiang, J.; Zhang, H.; Cai, C.; Shen, Q. Anal. Chem. 2018, 90, 4507-4513.

(22) Huang, R.; He, L.; Xia, Y.; Xu, H.; Liu, C.; Xie, H.; Wang, S.; Peng, L.; Liu, Y.; Liu, Y.; He, N.; Li, Z. Small 2019, 15, e1900735.

(23) Zhang, J.; Wang, L. L.; Hou, M. F.; Xia, Y. K.; He, W. H.; Yan, A.; Weng, Y. P.; Zeng, L. P.; Chen, J. H. Biosens. Bioelectron. 2018, $102,33-40$.

(24) Cha, T. G.; Pan, J.; Chen, H.; Robinson, H. N.; Li, X.; Mao, C.; Choi, J. H. J. Am. Chem. Soc. 2015, 137, 9429-9437.

(25) You, M.; Chen, Y.; Zhang, X.; Liu, H.; Wang, R.; Wang, K.; Williams, K. R.; Tan, W. Angew. Chem., Int. Ed. 2012, 51, 2457-2460.

(26) Ji, Y.; Zhang, L.; Zhu, L.; Lei, J.; Wu, J.; Ju, H. Biosens. Bioelectron. 2017, 96, 201-205.

(27) Qu, X.; Zhu, D.; Yao, G.; Su, S.; Chao, J.; Liu, H.; Zuo, X.; Wang, L.; Shi, J.; Wang, L.; Huang, W.; Pei, H.; Fan, C. Angew. Chem., Int. Ed. 2017, 56, 1855-1858.

(28) Pei, R.; Taylor, S. K.; Stefanovic, D.; Rudchenko, S.; Mitchell, T. E.; Stojanovic, M. N. J. Am. Chem. Soc. 2006, 128, 12693-12699.

(29) Li, N.; Du, M.; Liu, Y.; Ji, X.; He, Z. ACS Sens. 2018, 3, 12831290.

(30) Yehl, K.; Mugler, A.; Vivek, S.; Liu, Y.; Zhang, Y.; Fan, M.; Weeks, E. R.; Salaita, K. Nat. Nanotechnol. 2016, 11, 184-190.

(31) Xu, Z.; Chang, Y.; Chai, Y.; Wang, H.; Yuan, R. Anal. Chem. 2019, 91, 4883-4888.

(32) He, F.; Liu, H.; Guo, X.; Yin, B. C.; Ye, B. C. Anal. Chem. 2017, 89, 12968-12975.

(33) Tian, Q.; He, C.; Liu, G.; Zhao, Y.; Hui, L.; Mu, Y.; Tang, R.; Luo, Y.; Zheng, S.; Wang, B. Anal. Chem. 2018, 90, 6556-6562.

(34) Wan, Y.; Cheng, G.; Liu, X.; Hao, S. J.; Nisic, M.; Zhu, C. D.; Xia, Y. Q.; Li, W. Q.; Wang, Z. G.; Zhang, W. L.; Rice, S. J.; Sebastian, A.; Albert, I.; Belani, C. P.; Zheng, S. Y. Nat. Biomed. Eng. 2017, 1, 0058.

(35) Shao, H.; Im, H.; Castro, C. M.; Breakefield, X.; Weissleder, R.; Lee, H. Chem. Rev. 2018, 118, 1917-1950.

(36) Mori, K.; Hirase, M.; Morishige, T.; Takano, E.; Sunayama, H.; Kitayama, Y.; Inubushi, S.; Sasaki, R.; Yashiro, M.; Takeuchi, T. Angew. Chem., Int. Ed. 2019, 58, 1612-1615.

(37) Liu, C.; Xu, X.; Li, B.; Situ, B.; Pan, W.; Hu, Y.; An, T.; Yao, S.; Zheng, L. Nano Lett. 2018, 18, 4226-4232.

(38) Shigdar, S.; Lin, J.; Yu, Y.; Pastuovic, M.; Wei, M.; Duan, W. Cancer Sci. 2011, 102, 991-998.

(39) Song, Y.; Zhu, Z.; An, Y.; Zhang, W.; Zhang, H.; Liu, D.; Yu, C.; Duan, W.; Yang, C. J. Anal. Chem. 2013, 85, 4141-4149.

(40) Cai, S.; Luo, B.; Jiang, P.; Zhou, X.; Lan, F.; Yi, Q.; Wu, Y. Nanoscale 2018, 10, 14280-14289.

(41) Hisey, C. L.; Dorayappan, K. D. P.; Cohn, D. E.; Selvendiran, K.; Hansford, D. J. Lab Chip 2018, 18, 3144-3153.

(42) Ma, H.; Liu, J.; Ali, M. M.; Mahmood, M. A.; Labanieh, L.; Lu, M.; Iqbal, S. M.; Zhang, Q.; Zhao, W.; Wan, Y. Chem. Soc. Rev. 2015, 44, 1240-1256.

(43) Jiang, B.; Li, F.; Yang, C.; Xie, J.; Xiang, Y.; Yuan, R. Anal. Chem. 2015, 87, 3094-3098.

(44) Chen, X.; Lan, J.; Liu, Y.; Li, L.; Yan, L.; Xia, Y.; Wu, F.; Li, C.; Li, S.; Chen, J. Biosens. Bioelectron. 2018, 102, 582-588.

(45) Jiang, Y.; Shi, M.; Liu, Y.; Wan, S.; Cui, C.; Zhang, L.; Tan, W. Angew. Chem., Int. Ed. 2017, 56, 11916-11920.

(46) Zhang, K.; Yue, Y.; Wu, S.; Liu, W.; Shi, J.; Zhang, Z. ACS Sens. 2019, 4, 1245-1251.
(47) Etayash, H.; McGee, A.; Kaur, K.; Thundat, T. Nanoscale 2016, $8,15137-15141$

(48) Petersen, M.; Bondensgaard, K.; Wengel, J.; Jacobsen, J. P. J. Am. Chem. Soc. 2002, 124, 5974-5982.

(49) Mishra, S.; Lee, Y.; Park, J. W. Anal. Chem. 2018, 90, 1282412831.

(50) Kwon, H. J.; Jeong, J. S.; Bae, Y. K.; Choi, K.; Yang, I. Anal. Chem. 2019, 91, 3936-3943.

(51) Yang, I.; Han, M. S.; Yim, Y. H.; Hwang, E.; Park, S. R. Anal. Biochem. 2004, 335, 150-161.

(52) Wang, Y.; Chen, X.; Tian, B.; Liu, J.; Yang, L.; Zeng, L.; Chen, T.; Hong, A.; Wang, X. Theranostics 2017, 7, 1360-1372.

(53) Lao, R.; Song, S.; Wu, H.; Wang, L.; Zhang, Z.; He, L.; Fan, C. Anal. Chem. 2005, 77, 6475-6480.

(54) Hong, S. L.; Wan, Y. T.; Tang, M.; Pang, D. W.; Zhang, Z. L. Anal. Chem. 2017, 89, 6535-6542.

(55) Théry, C.; Witwer, K. W.; Aikawa, E.; Alcaraz, M. J.; Anderson, J. D.; Andriantsitohaina, R.; Antoniou, A.; Arab, T.; Archer, F.; AtkinSmith, G. K.; et al. J. Extracell. Vesicles 2018, 7, 1535750.

(56) Qi, H.; Yang, L.; Li, X.; Zhan, Q.; Han, D.; Zhao, J.; Hou, X.; Yuan, X. J. Mater. Chem. B 2018, 6, 2758-2768.

(57) Zhang, W.; Peng, P.; Kuang, Y.; Yang, J.; Cao, D.; You, Y.; Shen, K. Tumor Biol. 2016, 37, 4213-4221.

(58) Melo, S. A.; Sugimoto, H.; O'Connell, J. T.; Kato, N.; Villanueva, A.; Vidal, A.; Qiu, L.; Vitkin, E.; Perelman, L. T.; Melo, C. A.; Lucci, A.; Ivan, C.; Calin, G. A.; Kalluri, R. Cancer Cell 2014, 26, 707-721.

(59) Jung, C.; Allen, P. B.; Ellington, A. D. Nat. Nanotechnol. 2016, $11,157-163$.

(60) Jung, C.; Allen, P. B.; Ellington, A. D. ACS Nano 2017, 11, $8047-8054$.

(61) Qian, Y.; Wang, C.; Gao, F. Biosens. Bioelectron. 2015, 63, 425431.

(62) Cao, Y.; Li, L.; Han, B.; Wang, Y.; Dai, Y.; Zhao, J. Biosens. Bioelectron. 2019, 141, 111397.

(63) Cserni, G.; Chmielik, E.; Cserni, B.; Tot, T. Virchows Arch. 2018, 472, 697-703.

(64) Corkery, B.; Crown, J.; Clynes, M.; O’Donovan, N. Ann. Oncol. 2009, 20, 862-867.

(65) Song, Y.; Shi, Y.; Huang, M.; Wang, W.; Wang, Y.; Cheng, J.; Lei, Z.; Zhu, Z.; Yang, C. Angew. Chem., Int. Ed. 2019, 58, 22362240.

(66) Lin, Y.; Jia, J.; Yang, R.; Chen, D.; Wang, J.; Luo, F.; Guo, L.; Qiu, B.; Lin, Z. Anal. Chem. 2019, 91, 3717-3724.

(67) Cao, H.; Wang, Y.; Gao, Y.; Deng, X.; Cong, Y.; Liu, Y.; Jiang, X. Angew. Chem., Int. Ed. 2019, 58, 1626-1631. 


\section{Supplementary Information}

\section{Multi-legged Exosomal Walker for Electrochemical Detection of}

\section{Exosomes}

Liangliang Wang $g^{\dagger, \star}$, Yuru Wang ${ }^{\dagger, \star}$, Juan Li ${ }^{\S}$, Lupeng Zeng $g^{\dagger, \star}$, Yijuan Liao", Huifang Mao" , Wenqian Chen ${ }^{\dagger, \star}$, Jing Zhang*,/, Huanghao Yang*, , Jinghua Chen",,+

†Department of Pharmaceutical Analysis, The School of Pharmacy, Fujian Medical University, Fuzhou, Fujian Province 350122 (P. R. China) E-mail: cjh_huaxue@126.com

\$Fujian Key Laboratory of Drug Target Discovery and Structural and Functional Research, The School of Pharmacy, Fujian Medical University, Fuzhou, Fujian Province 350122 (P. R. China) E-mail: cjh_huaxue@126.com

$\S$ MOE Key Laboratory for Analytical Science of Food Safety and Biology, State Key Laboratory of Photocatalysis on Energy and Environment, College of Chemistry, Fuzhou University, Fuzhou, Fujian Province 350108 (P. R. China) E-mail: hhyang@fzu.edu.cn

"Department of Chemical Biology, College of Life Sciences, Fujian Agriculture and Forestry University, Fuzhou, Fujian Province 350002 (P. R. China) E-mail: 1601225385@qq.com

\section{Table of contents}

1. Partial experimental methods used in this work.

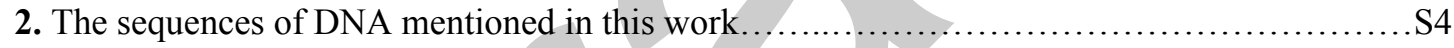

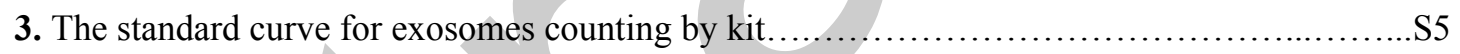

4. The characterization of EGFR aptamers functionalized magnetic beads.........................S5

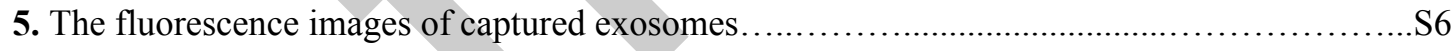

6. The DLS measurement of MDA-MB-231 cells derived exosomes isolated by ultracentrifugation. S6

7. The TEM image of the released exosomal walkers.

8. The feasibility characterization by CV and EIS

9. The TEM image of the exosomal walkers after the walking process.

10. The standard fluorescence curve of FAM-labeled DNA "legs". . .59

11. The comparison of walking steps of various DNA walkers based on strand displacement....S10

12. Optimization of experimental parameters for the isolation process

13. The LNA-modified complementary strands of EGFR DNA aptamer. 
15. Optimization of experimental parameters for the walking process

16. The comparison of current methods for exosomes detection

17. The TEM images of MCF-7 cells and MCF-10A cells derived exosomes.

18. The DLS measurements of MCF-7 cells and MCF-10A cells derived exosomes

19. The repeated detection of exosomes for 5 times

20. The current intensity of initial detection and after regeneration.

21. References

\section{EXPERIMENTAL METHODS}

Reagents. ExoELISA-ULTRA CD63 kit was purchased from System Biosciences (SBI). Exosomal proteins lysis buffer was purchased from Weihui Biotechnology Co., Ltd (Beijing, China). Radio immunoprecipitation assay (RIPA) lysis buffer was purchased from Beyotime. Pierce bicinchoninic acid (BCA) proteins assay kit was purchased from Thermo Fisher Scientific. Sodium dodecyl sulfate-polyacrylamide gel electropheresis (SDS-PAGE) gel preparation kit, paraformaldehyde and glutaraldehyde were purchased from Beijing solarbio sciences \& technology Co., Ltd (Beijing, China). Polyvinylidene fluoride membrane (PVDF) was purchased from Beijing Dingguo Changsheng Biotechnology Co., Ltd (Beijing, China). Tween-20 and 20× Tris buffered saline (TBS) were purchased from Sangon Biotech Co., Ltd (Shanghai, China). CD63 antibody and anti-CD63 antibody, TSG101 antibody and anti-TSG101, EGFR antibody and anti-EGFR antibody were purchased from Abcam.

Exosomes counting by ExoELISA-ULTRA CD63 kit. Firstly, exosomes were added in the microtiter plate provided in the kit, and incubated at $37{ }^{\circ} \mathrm{C}$ overnight. After three rinses, specific rabbit anti-human CD63 antibody (System Biosciences) was added and incubated for $1 \mathrm{~h}$ at room temperature. Then, the plate was incubated with HRP-conjugated goat anti-rabbit antibody (SBI) for $1 \mathrm{~h}$ after washing. After the final washing, the reaction was performed with super-sensitive 3 , 3', 5, 5'-Tetramethylbenzidine (TMB) substrate followed by blocking with a stop buffer. Finally, the optical densities were recorded at $450 \mathrm{~nm}$ using Multiskan GO microplate spectrophotometer (Thermo Fisher Scientific, U.S.A.).

Transmission electron microscopy (TEM). $10 \mu \mathrm{L}$ drops of the mixture of exosomes and $4 \%$ paraformaldehyde in PBS were firstly absorbed on formvar carbon-coated grids for $20 \mathrm{~min}$. Then, $1 \%$ glutaraldehyde were added into grid to fix exosomes for $5 \mathrm{~min}$ and washed three times with deionized water. The grids were negatively stained with $1 \%$ aqueous uranyl acetate for $5 \mathrm{~min}$. After drying, the samples were visualized by TEM.

Dynamic light scattering (DLS). The effective hydrodynamic diameters of exosomes were measured by Litesizer 500 (Anton Paar, Austria) equipped with $35 \mathrm{~mW}$ laser diode light $(\lambda=658$ $\mathrm{nm}$ ) and collecting the scattered light at an angle of $90^{\circ}$. Samples were diluted with filtered PBS to 
$1 \mathrm{~mL}$, and then poured in solvent-resistant cuvette for light scattered measurement at a fixed position. The target temperature was controlled at $25^{\circ} \mathrm{C}$.

Western blot analysis. Cells and exosomes were lysed in RIPA buffer and exosomal proteins lysis buffer, respectively. The proteins samples were quantified using the BCA assay. Then, the denatured proteins were separated by $6 \%$ or $12 \%$ SDS-PAGE in electrophoretic buffer $(25 \mathrm{mM}$ Tris, $192 \mathrm{mM}$ glycine, $0.5 \% \mathrm{SDS}$ ) at constant voltage. Next, half-dry electrophoretic transfer was applied to transfer the proteins from gels to PVDF membranes that need activation with methanol in Towbin transfer buffer (25 mM Tris, $192 \mathrm{mM}$ glycine, $20 \%$ methanol) at $300 \mathrm{~mA}$. After blocking with $5 \%$ non-fat powdered milk in TBST buffer $(1 \times$ TBS containing $0.05 \%$ Tween-20, $\mathrm{pH}$ 7.4) for $2 \mathrm{~h}$ at room temperature, the PVDF membranes were incubated with $200 \mu \mathrm{l}$ drops of primary antibodies (CD63 antibody, TSG101 antibody or EGFR antibody) solution overnight at 4 ${ }^{\circ} \mathrm{C}$. Subsequently, the blots were incubated with HRP-conjugated secondary antibody at room temperature for $1 \mathrm{~h}$ (Abcam). Finally, an enhanced chemiluminescence reagent (Thermo Fisher Scientific) was used to visualize the immunoreactive bands, and the images were obtained using an ECL detecting system (Bio-Rad, U.S.A.).

Zeta potential analysis. Zeta potential of samples was analyzed by Litesizer 500 (Anton Paar, Austria) with electrophoretic light scattering (ELS) by $35-\mathrm{mW}$ diode laser $(\lambda=658 \mathrm{~nm})$ and at $15^{\circ}$ detection angle. The electrodes were inserted into a square plastic cell with about $1 \mathrm{~mL}$ sample solution. The temperature was set at $25^{\circ} \mathrm{C}$ and the sample was allowed to equilibrate for $5 \mathrm{~min}$. 
Table S1. The sequences of DNA mentioned in this work

\begin{tabular}{|c|c|}
\hline Oligo Name & Sequence (from 5' to 3') \\
\hline \multirow{3}{*}{ EGFR aptamer 1(Ref. 1) } & TACCAGTGCGATGCTCAGTGCCGTTTCTTCTCT \\
\hline & TTCGCTTTTTTTGCTTTTGAGCATGCTGACGCAT \\
\hline & TCGGTTGAC \\
\hline \multirow{3}{*}{ EGFR aptamer 2} & biotin-TACCAGTGCGATGCTCAGTGCCGTTTCTT \\
\hline & CTCTTTCGCTTTTTTTGCTTTTGAGCATGCTGAC \\
\hline & GCATTCGGTTGAC \\
\hline \multirow{3}{*}{ EGFR aptamer 3} & biotin-TACCAGTGCGATGCTCAGTGCCGTTTCTT \\
\hline & СTCTTTCGCTTTTTTTGCTTTTGAGCATGCTGAC \\
\hline & GCATTCGGTTGAC-Cy3 \\
\hline \multirow{3}{*}{ EGFR aptamer 4} & TACCAGTGCGATGCTCAGTGCCGTTTCTTCTCT \\
\hline & TTCGCTTTTTTTGCTTTTGAGCATGCTGACGCAT \\
\hline & TCGGTTGAC-Cy3 \\
\hline \multirow{3}{*}{$\begin{array}{l}\text { Lock nucleic acid (LNA)-modified } \\
\text { complementary strand }\end{array}$} & GTC $^{\mathrm{L}}$ AACCGAATGLCGTCAGCATGL CTCAAAAG ${ }^{\mathrm{L}}$ \\
\hline & CAAAAAAAG ${ }^{\mathrm{L}} \mathrm{CGAAAG}^{\mathrm{L}} \mathrm{AGAAGAAACG^{ \textrm {L } } \mathrm { GCAC } \mathrm { A }}$ \\
\hline & TGAGLCATCGCACTGG ${ }^{\mathrm{L}} \mathrm{TA}$ \\
\hline Cholesterol-labeled DNA "leg" & Cholesterol-CGACATCTAACCTAGCTCACTGAC \\
\hline \multirow{2}{*}{$\begin{array}{l}\text { FAM- and cholesterol-labeled DNA } \\
\text { "leg" }\end{array}$} & Cholesterol-CGACATCTAACCTAGCTCACTGAC \\
\hline & -FAM \\
\hline \multirow{2}{*}{ Hairpin probe $1(\mathrm{H} 1)$} & HS-GTCAGTGAGCTAGGTTAGATGTCGCCATGT \\
\hline & GTAGACGACATCTAACCTAGC \\
\hline \multirow{2}{*}{ Fc-labeled hairpin probe $1(\mathrm{Fc}-\mathrm{H} 1)$} & HS-GTCAGTGAGCTAGGTTAGATGTCGCCATGT \\
\hline & GTAGACGACATCTAACCTAGC-Fc \\
\hline \multirow{2}{*}{$\begin{array}{l}\text { Biotin-labeled hairpin probe } 2 \\
\text { (biotin-H2) }\end{array}$} & biotin-AGATGTCGTCTACACATGGCGACATCTAA \\
\hline & CCTAGCCCATGTGTAGA \\
\hline \multirow{2}{*}{ Hairpin probe $2(\mathrm{H} 2)$} & AGATGTCGTCTACACATGGCG \\
\hline & GCCCATGTGTAGA \\
\hline
\end{tabular}

Cy3, FAM and Fc represent Cyanines 3, Carboxyfluorescein and Ferrocene, respectively. L stands for the modification of LNA. 


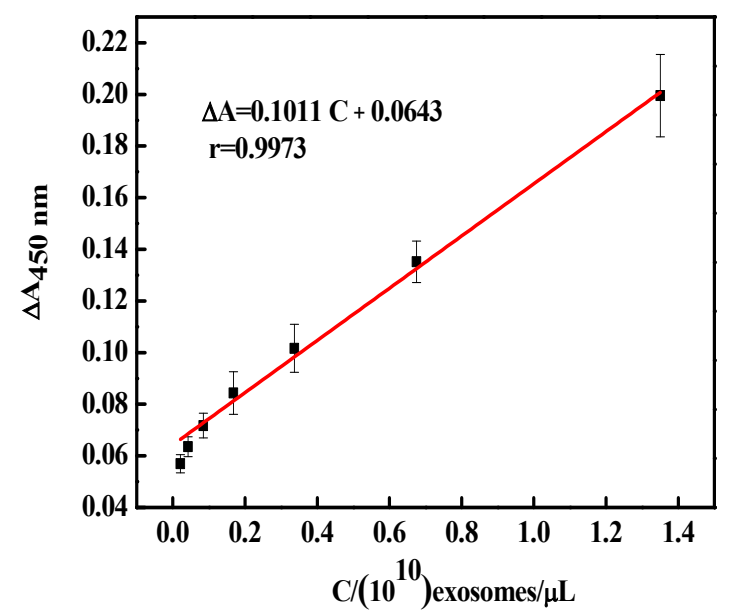

Figure S1. The standard curve for exosomes counting by ExoELISA-ULTRA CD63 kit.

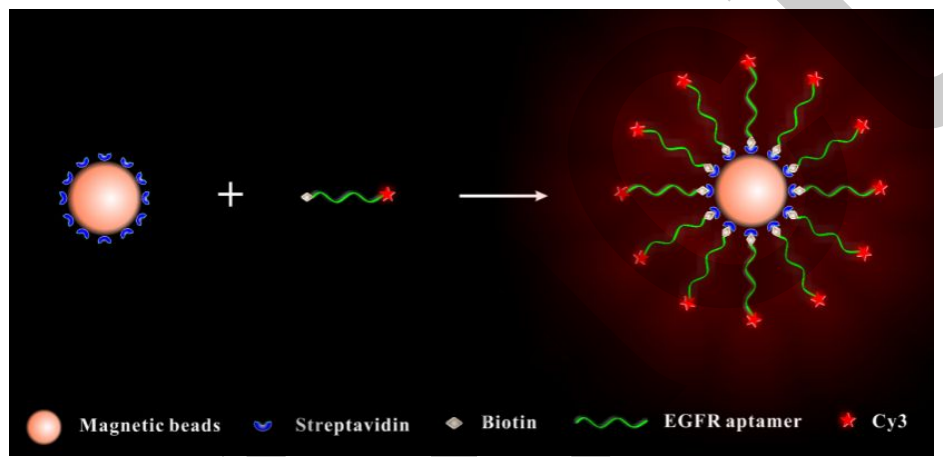

\section{A}

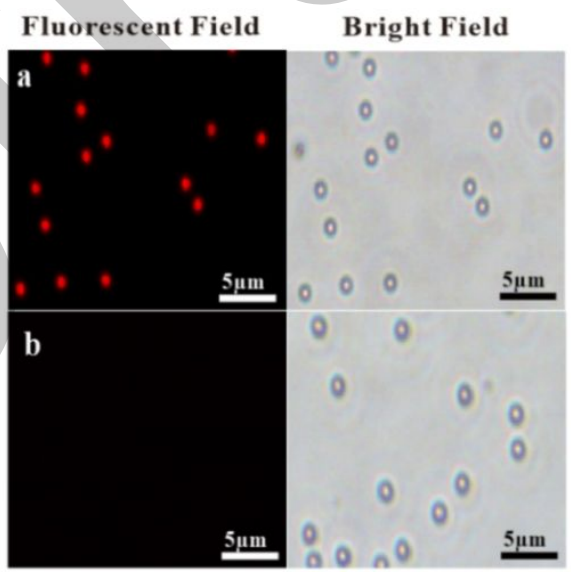

B

Figure S2. The characterization of EGFR aptamers functionalized magnetic beads (EAmbs). A. The schematic diagram of EAmbs formation. B. The fluorescence images of streptavidin-modified magnetic beads (SA-mbs) reacted with Cy3-labeled EGFR aptamer modified with (a) or without (b) biotin under the inverted fluorescence microscope. 


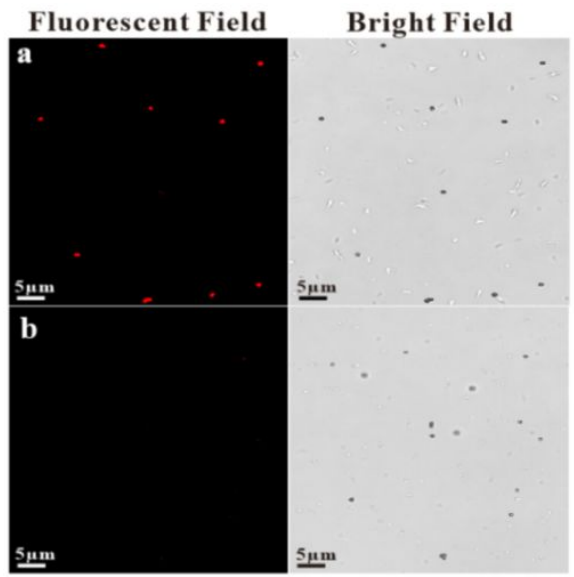

Figure S3. The fluorescence images of exosomes captured by EAmbs (a) or SA-mbs (b), and colored by $2 \mu \mathrm{g} / \mathrm{mL}$ membrane dye DiI under the laser confocal fluorescence microscopy.

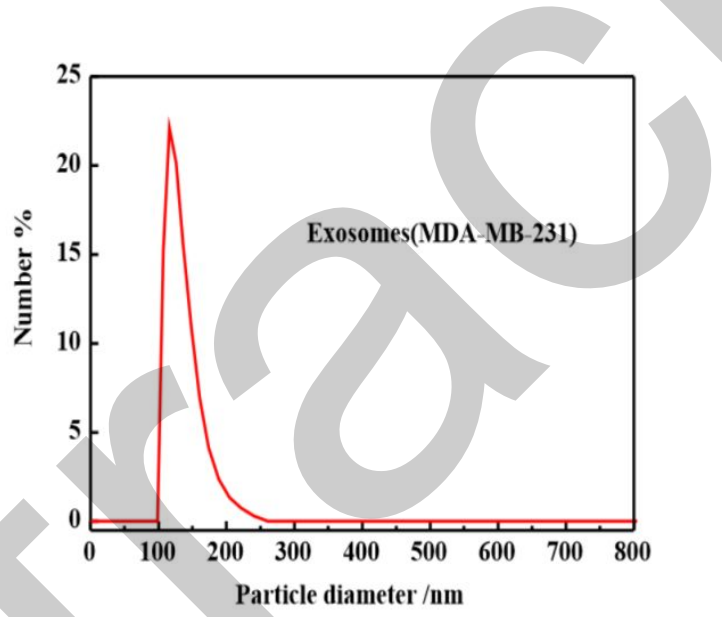

Figure S4. The DLS measurement of MDA-MB-231 cells derived exosomes isolated by ultracentrifugation. 


$$
\frac{1 .}{e^{e^{e^{2}}}}
$$




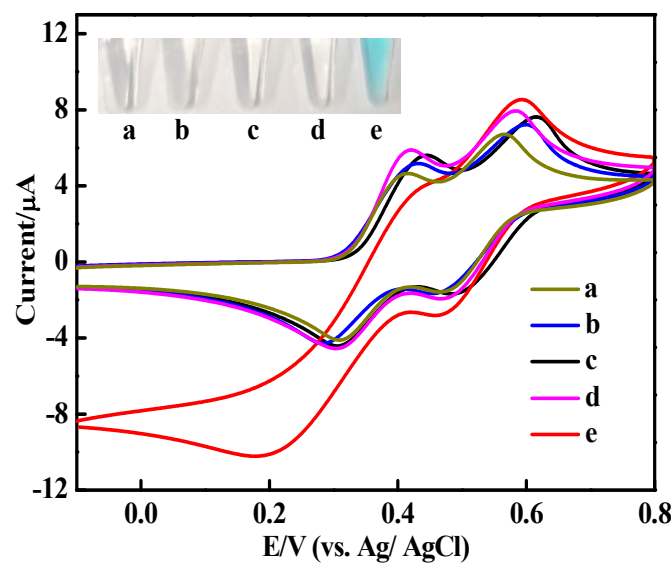

A

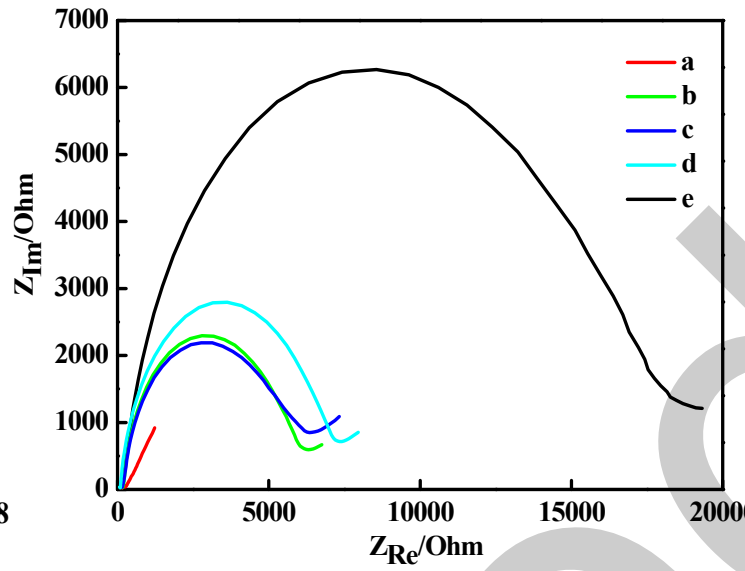

B

Figure S6. The feasibility characterization by CV and EIS. A. The CVs of different electrodes in TMB- $\mathrm{H}_{2} \mathrm{O}_{2}$ solution. (a) Bare gold electrode (GE), (b) $\mathrm{MCH} / \mathrm{H} 1 / \mathrm{GE}$, (c) $\mathrm{MCH} / \mathrm{H} 1 / \mathrm{GE}$ incubated with biotin- $\mathrm{H} 2$, (d) $\mathrm{MCH} / \mathrm{H} 1 / \mathrm{GE}$ incubated with exosomal walkers, (e) $\mathrm{MCH} / \mathrm{H} 1 / \mathrm{GE}$ incubated with exosomal walkers and biotin-H2. Inset: The color change of $\mathrm{TMB}-\mathrm{H}_{2} \mathrm{O}_{2}$ solution after immersing different electrodes. B. The EIS of the different electrodes in $0.1 \mathrm{M} \mathrm{KCl}$ aqueous solution containing $5 \mathrm{mM}(1: 1)\left[\mathrm{Fe}(\mathrm{CN})_{6}\right]^{3-/ 4}$. (a) Bare GE, (b) $\mathrm{MCH} / \mathrm{H} 1 / \mathrm{GE}$, (c) $\mathrm{MCH} / \mathrm{H} 1 / \mathrm{GE}$ incubated with biotin-H2, (d) MCH/H1/GE incubated with exosomal walkers, (e) MCH/H1/GE incubated with biotin-H2 and exosomal walkers.

As shown in Figure S6, cyclic voltammogram (CV) and electrochemical impedance spectroscopy (EIS) were measured to further study the walking process of exosomal walkers along H1 DNA tracks. As CV curves of different electrodes (Figure S6A) show, MCH/H1/GE (curve b) has two pairs of redox peaks in $\mathrm{H}_{2} \mathrm{O}_{2}$ /TMB solution as well as bare $\mathrm{GE}$ (curve a). Upon incubating with biotin-H2 DNA (curve c), the curve displays little change. Likewise, there are similar redox peaks while exosomal walkers attached on $\mathrm{H} 1$ (curve d). In the coexistence of exosomal walkers and biotin-H2 DNA (curve e), the $\mathrm{MCH} / \mathrm{H} 1 / \mathrm{GE}$ shows conspicuous catalytic reduction peak accompanied by colorless solution changing to blue color. Additionally, Nyquist curves of different assembled GE were depicted in Figure S6B. The diameter of semicircle curve is equivalent to the electron transfer resistance (Rct) on electrode interface. The bare GE (curve a) have a minuscule semi-circle as well as negligible Rct, showing a rapid electron transfer course of $\left[\mathrm{Fe}(\mathrm{CN})_{6}\right]^{3-4-}$. Owing to electrostatic repulsion between negatively charged phosphate back-bones and $\left[\mathrm{Fe}(\mathrm{CN})_{6}\right]^{3-/ 4-}$, Rct rose with the modification of $\mathrm{H} 1 \mathrm{DNA}$ (curve b). When $\mathrm{MCH} / \mathrm{H} 1 / \mathrm{GE}$ incubated with biotin-H2 DNA (curve c) or negatively charged exosomal walkers (curve d), Rct had no obvious change, or had small increase. Nevertheless, Rct (curve e) sharply boosted while $\mathrm{MCH} / \mathrm{H} 1 / \mathrm{GE}$ was immersed in solution containing biotin-H2 DNA and exosomal walkers. Summarily, the CV and EIS have consistent results, further verifying the feasibility of this walking strategy. 


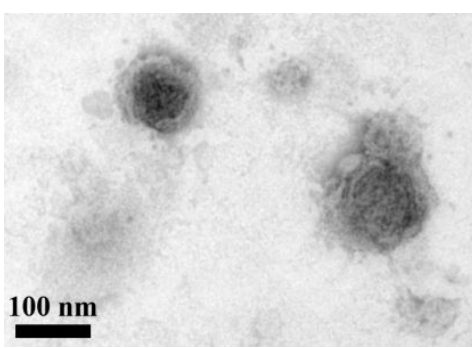

Figure S7. The TEM image of the exosomal walkers after the walking process.

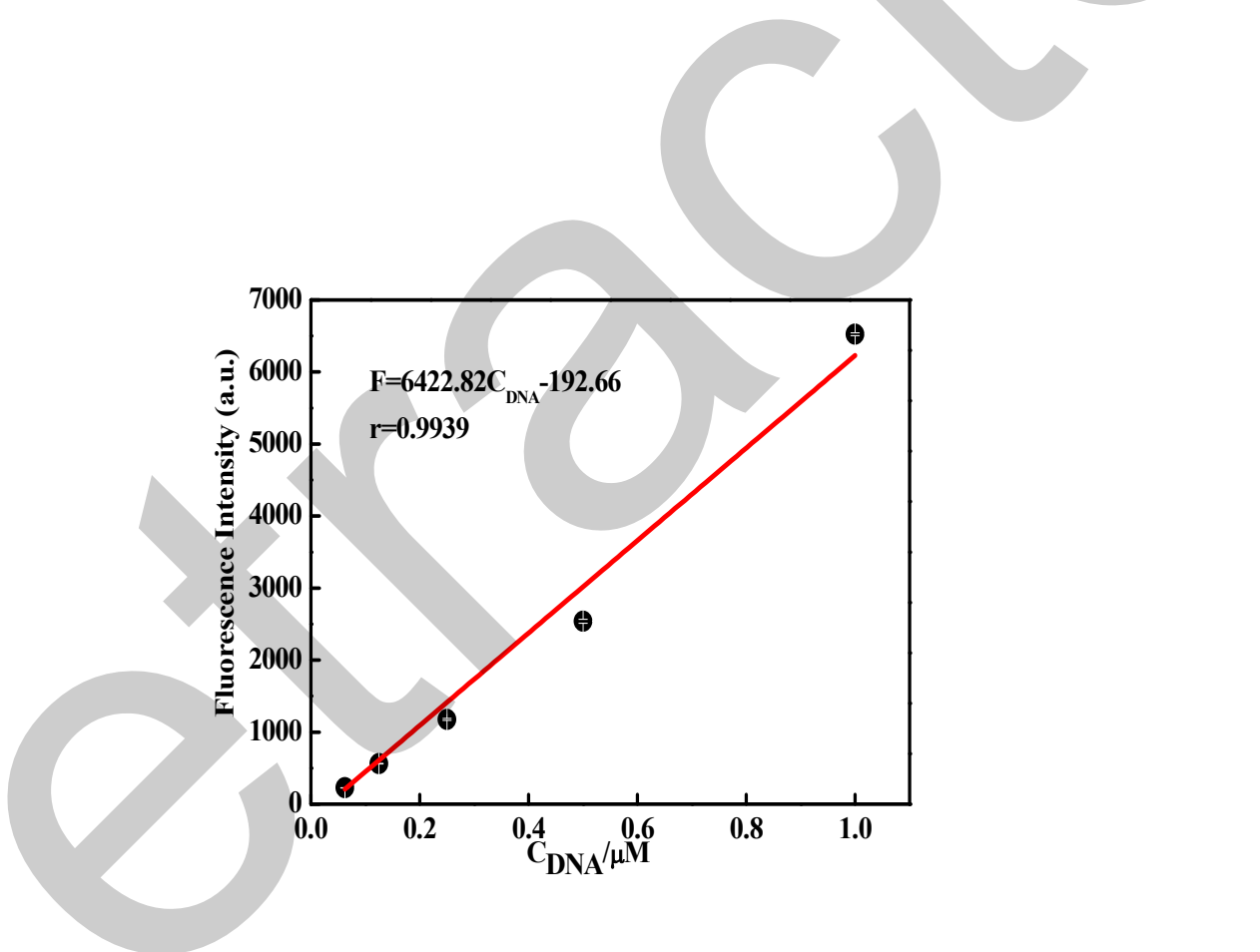

Figure S8. The standard fluorescence curve of FAM-labeled DNA "legs". Error bar is based on triplicate experiments. 
Table S2. The comparison of walking steps of various DNA walkers based on strand displacement

\begin{tabular}{cccc}
\hline \multirow{2}{*}{ "Body" of walker } & "Legs" numbers & Walking steps & Ref. \\
& & & 2 \\
\hline Duplex DNA & Two & 5 & 3 \\
\hline Duplex DNA & Two & 3 & 4 \\
\hline DNA structure & Three & 6 & 5 \\
\hline Single strand DNA & Two & 36 & 6 \\
\hline Cleat & One & 47 & This work \\
\hline Exosomes & $473^{*}$ & 55 &
\end{tabular}

*The number of "legs" per exosome was determined using the fluorescence method according to the reference. ${ }^{7}$ Firstly, we used FAM-labeled DNA "legs" to anchor the exosomes captured by aptamers functionalized magnetic beads, and established the fluorescence standard curve of FAM-labeled DNA "legs" (Figure S8). After the modification, the fluorescence of the supernatant obtained by magnetic separation was measured. The resulting fluorescence value can be used to calculate the DNA concentration in the supernatant after comparing the standard curve. By using the initial amount of DNA minus the amount of free DNA in the supernatant, we could obtain the number of DNA "legs" according to the equation $\left(\mathrm{N}=\left(\mathrm{C}_{\text {initial }}-\mathrm{C}_{\text {supernatant }}\right) \times \mathrm{V} \times\right.$

$\left.\mathrm{N}_{\mathrm{A}} / \mathrm{N}_{\text {exosomes }}\right)$. $\mathrm{C}_{\text {initial }}$ is the initial concentration of DNA; $\mathrm{C}_{\text {supernatant }}$ is the DNA concentration of the supernatant obtained by magnetic separation after reaction; $\mathrm{V}$ is the reaction volume; $\mathrm{N}_{\mathrm{A}}$ is the Avogadro constant $\left(\sim 6.02 \times 10^{23} / \mathrm{mol}\right)$. 

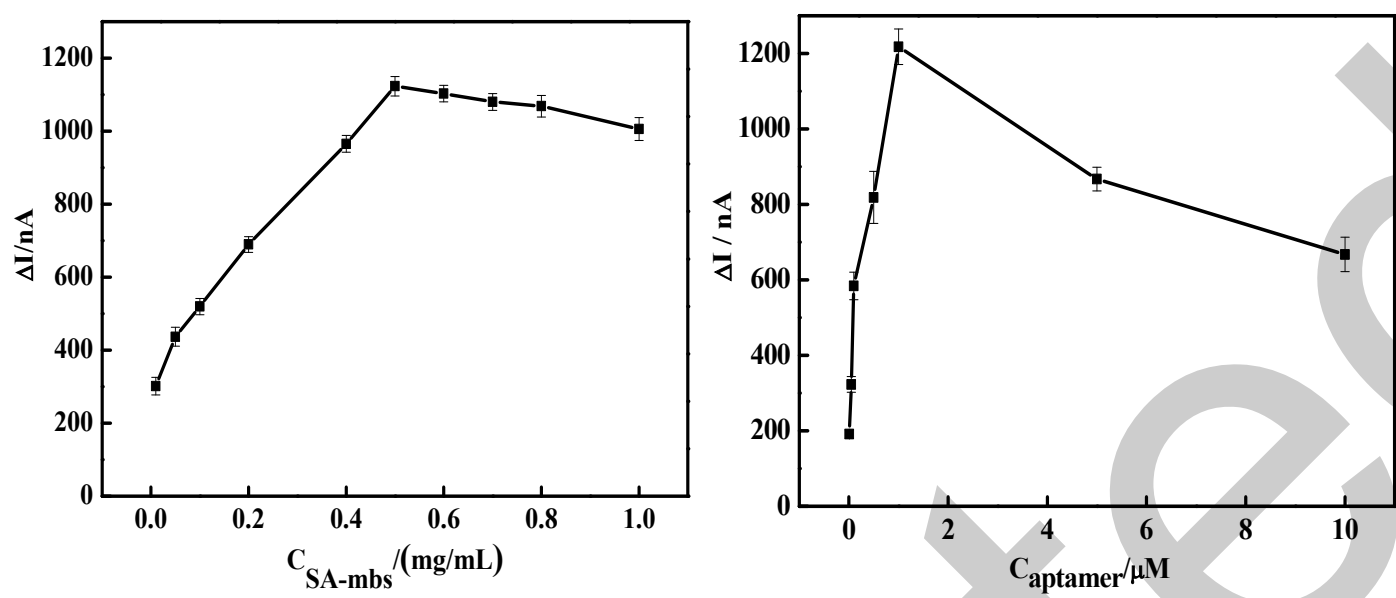

A

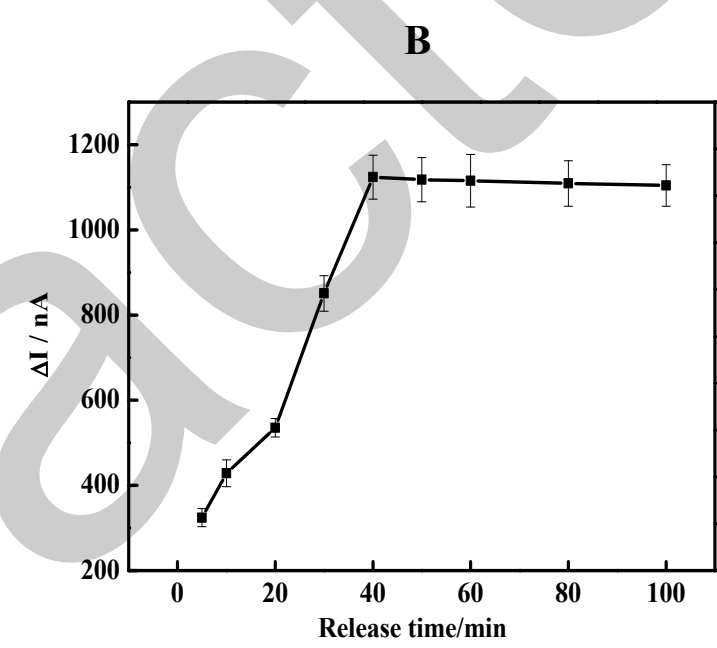

C

D

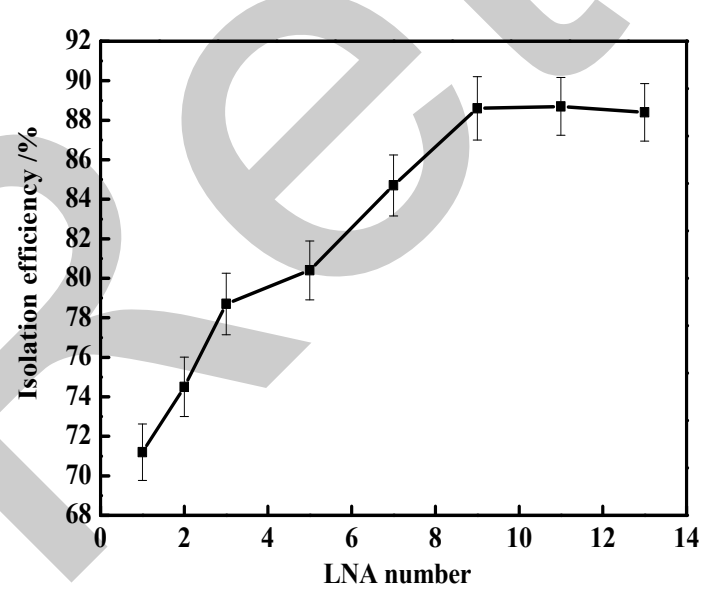

E

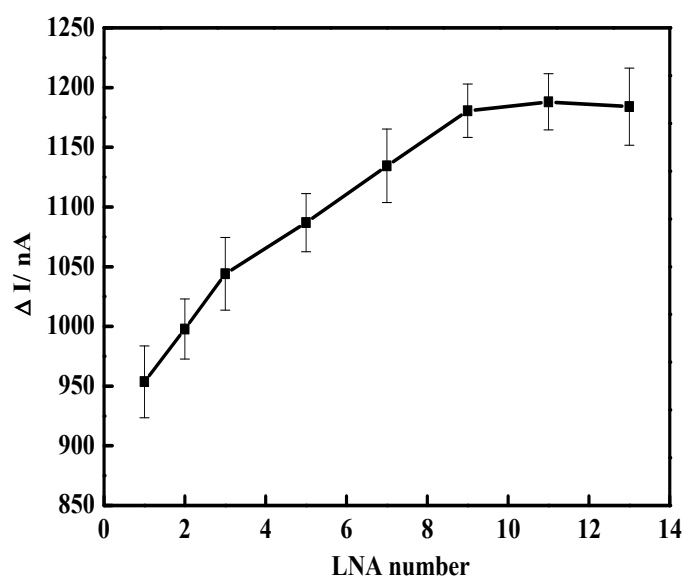

F

Figure S9. Optimization of experimental parameters in the formation process of multi-legged exosomal walkers. The current changes $(\Delta \mathrm{I})$ induced by SA-mbs concentration $(\mathrm{A})$, DNA aptamers concentration (B), capture time (C) and release time (D) on the GE were measured, respectively. The effects of LNA number on isolation efficiency of exosomes (E) and $\Delta \mathrm{I}$ of the 
GE (F) were also analyzed.

Table S3. The LNA-modified complementary strands of EGFR DNA aptamer

\begin{tabular}{|c|c|}
\hline Oligo Name & Sequence (from 5' to 3') \\
\hline \multirow{2}{*}{ complementary strand 1} & GTC $^{\mathrm{L}}$ AACCGAATGCGTCAGCATGCTCAAAAGCAAAAAAA \\
\hline & GCGAAAGAGAAGAAACGGCACTGAGCATCGCACTGGTA \\
\hline \multirow{2}{*}{ complementary strand 2} & GTC $^{\mathrm{L}}$ AACCGAATGCGTCAGCATGCTCAAAAGCAAAAAAA \\
\hline & GLCGAAAGAGAAGAAACGGCACTGAGCATCGCACTGGTA \\
\hline \multirow{3}{*}{ complementary strand 3} & GTC $^{\mathrm{L}}$ AACCGAATGCGTCAGCATGCTCAAAAGCAAAAAAA \\
\hline & GLCGAAAGAGAAGAAACGGCACTGAGCATCGCACTGG $^{\mathrm{L} T}$ \\
\hline & $\mathrm{A}$ \\
\hline \multirow{3}{*}{ complementary strand 4} & GTC $^{\mathrm{L}}$ AACCGAATG ${ }^{\mathrm{L}}$ CGTCAGCATGCTCAAAAGCAAAAAA \\
\hline & AG ${ }^{\mathrm{L}}$ CGAAAGAGAAGAAACGGCACTGAG ${ }^{\mathrm{L}} \mathrm{CATCGCACTGG}$ \\
\hline & LTA \\
\hline \multirow{3}{*}{ complementary strand 5} & GTC $^{\mathrm{L}}$ AACCGAATG ${ }^{\mathrm{L}}$ CGTCAGCATG $^{\mathrm{L}}$ CTCAAAAGCAAAAAA \\
\hline & AG $^{\mathrm{L}} C G A A A G A G A A G A A A C G^{\mathrm{L}}{ } C A C T G A G^{\mathrm{L}}{ }^{2} A T C G C A C T G$ \\
\hline & $G^{\mathrm{L} T A}$ \\
\hline \multirow{3}{*}{ complementary strand 6} & GTC $^{\mathrm{L}}$ AACCGAATG $^{\mathrm{L}}$ CGTCAGCATG ${ }^{\mathrm{L}} \mathrm{CTCAAAAG}^{\mathrm{L}}$ CAAAAA \\
\hline & AAG $^{\mathrm{L}} C G A A A G^{\mathrm{L}} A G A A G A A A C G^{\mathrm{L}} \mathrm{GCACTGAG}^{\mathrm{L}} \mathrm{CATCGCACT}$ \\
\hline & GG $^{\mathrm{L} T A}$ \\
\hline \multirow{3}{*}{ complementary strand 7} & GTC $^{\mathrm{L}}$ AACC $^{\mathrm{L}}{ }^{\mathrm{AAT}}{ }^{\mathrm{L}} \mathrm{CGTCAG}^{\mathrm{L}} \mathrm{CATG}^{\mathrm{L}} \mathrm{CTCAAAAG}^{\mathrm{L}}$ CAAAA \\
\hline & 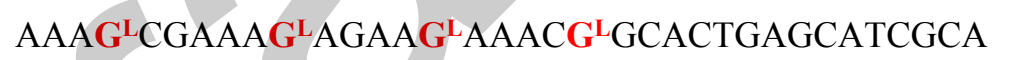 \\
\hline & CTGGLTA \\
\hline complementary strand 8 & 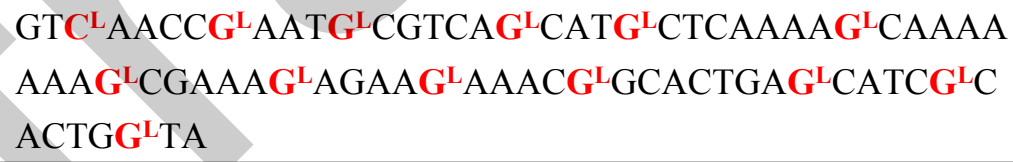 \\
\hline
\end{tabular}

L The letter "L" stands for lock nucleic acid (LNA) modification. 
Table S4. The isolation efficiency of exosomes

\begin{tabular}{|c|c|c|c|}
\hline Batches & 1 & 2 & 3 \\
\hline $\begin{array}{l}\text { The numbers before capture }\left(\text { Number }_{\text {total }}\right) \\
\qquad /(\text { exosomes } / \mu \mathrm{L})\end{array}$ & $1.21 \times 10^{10}$ & $5.82 \times 10^{9}$ & $1.36 \times 10^{9}$ \\
\hline $\begin{array}{l}\text { The numbers remaining in liquid } \\
\text { supernatant after capture } \\
\text { (Number }{ }_{\text {remaining }} /(\text { exosomes } / \mu \mathrm{L})\end{array}$ & $2.26 \times 10^{9}$ & $8.15 \times 10^{8}$ & $10^{8}$ \\
\hline $\begin{array}{l}\text { The numbers in liquid supernatant after } \\
\text { release (Number } \text { release } 1) \text { without LNA } \\
\text { modification/(exosomes } / \mu \mathrm{L})\end{array}$ & $6.72 \times 10^{9}$ & & )$^{8}$ \\
\hline Isolation efficiency $1 *$ & $68.29 \%$ & $69.81 \%$ & $64.23 \%$ \\
\hline Average of isolation efficiency 1 & & $7.44 \pm 2.88 \%$ & \\
\hline $\begin{array}{c}\text { The numbers in liquid supernatant after } \\
\text { release (Number } \text { release }^{2} \text { ) with LNA } \\
\text { modification/(exosomes } / \mu \mathrm{L})\end{array}$ & $0.874 \times 10^{10}$ & $4.379 \times 10^{9}$ & $1.08 \times 10^{9}$ \\
\hline Isolation efficiency $2^{*}$ & $88.82 \%$ & $87.49 \%$ & $90.68 \%$ \\
\hline Average of isolation efficiency 2 & & $9.00 \pm 1.60 \%$ & \\
\hline
\end{tabular}

$*$ The isolation efficiency $=$ Number $_{\text {release }} /\left(\right.$ Number $_{\text {total }}-$ Number $\left._{\text {remaining }}\right)$. 


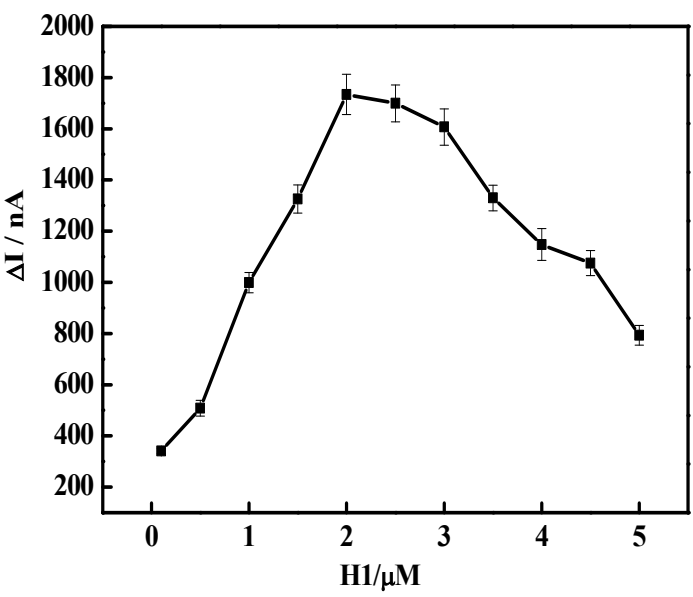

A

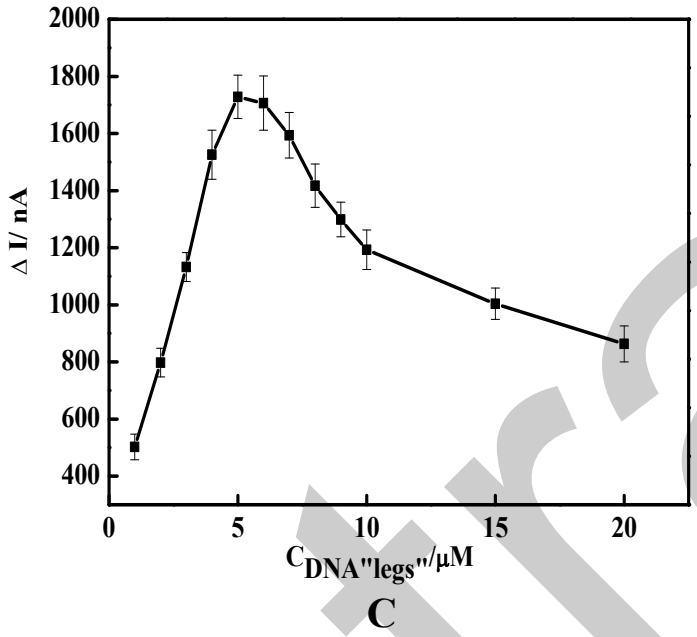

C

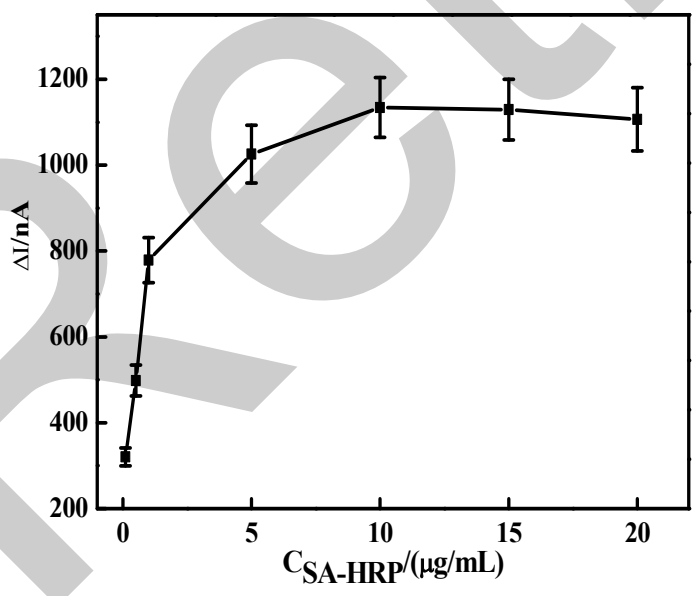

$\mathbf{E}$

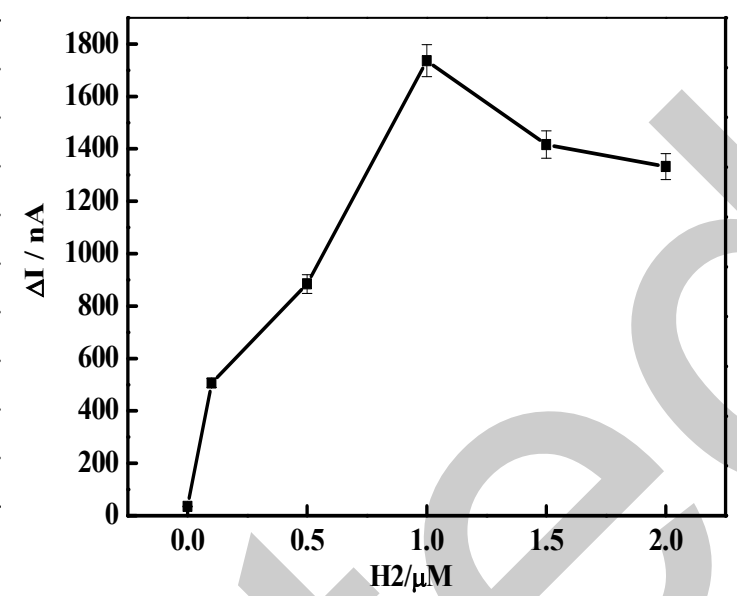

B

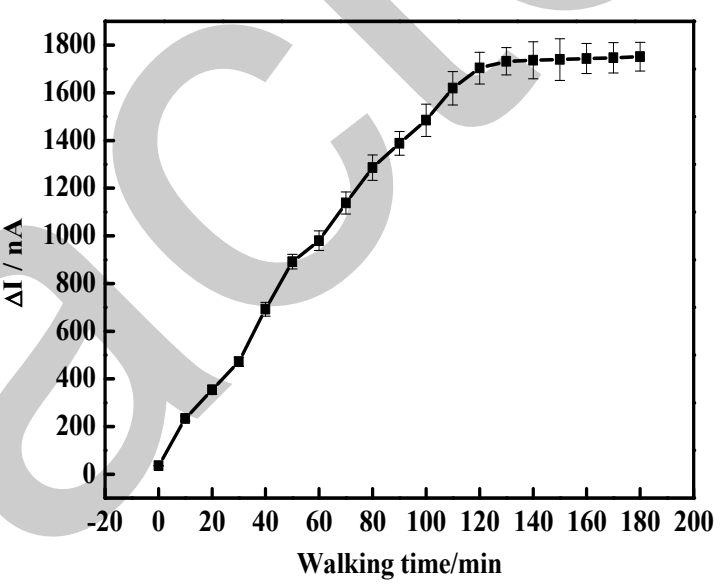

D

Figure S10. Optimization of experimental parameters in the walking process of exosomal walkers. The current changes $(\Delta \mathrm{I})$ induced by $\mathrm{H} 1$ DNA concentration (A), H2 DNA concentration (B), DNA "legs" concentration (C), walking time (D), SA-HRP concentration (E) on the GEs were measured, respectively. 
Table S5. The comparison of current methods for exosomes detection

\begin{tabular}{|c|c|c|}
\hline Methods & LOD (exosomes $/ \mu \mathrm{L})$ & Ref. \\
\hline SERS & 27 & 8 \\
\hline SERS immunoassay & 0.50 & 9 \\
\hline Surface plasmon resonance & 5 & 10 \\
\hline The droplet digital ExoELISA & 10 & 11 \\
\hline Magnetic-based microfluidic device & 4.39 & 12 \\
\hline $\begin{array}{l}\text { Dual-signal amplification platform for fluorescence } \\
\text { biosensing }\end{array}$ & 100 & \\
\hline $\begin{array}{c}\mathrm{Ti}_{3} \mathrm{C}_{2} \mathrm{MXenes} \mathrm{based} \mathrm{self-standard} \mathrm{ratiometric} \mathrm{fluorescence} \\
\text { resonance energy transfer platform }\end{array}$ & & 14 \\
\hline $\begin{array}{l}\text { Exosome-oriented, aptamer nanoprobe-enabled surface } \\
\text { proteins fluorescence detection }\end{array}$ & & 15 \\
\hline Molecular recognition-based DNA nanodevices & $4 \times 10^{3}$ & 16 \\
\hline $\begin{array}{l}\text { Dual signal amplification fluorescence method based on } \\
\text { DNA dendrimer self-assembly }\end{array}$ & $1.16 \times 10^{3}$ & 17 \\
\hline $\begin{array}{l}\text { Bridging exosome and liposome through } \\
\text { zirconium-phosphate coordination chemistry }\end{array}$ & $60 \times 10^{3}$ & 18 \\
\hline $\begin{array}{c}\mathrm{Ti}_{3} \mathrm{C}_{2} \mathrm{MXenes} \mathrm{nanosheets} \mathrm{catalyzed} \mathrm{electrogenerated} \\
\text { chemiluminescence biosensor }\end{array}$ & 125 & 19 \\
\hline $\begin{array}{c}\text { Aptamer-capped } \mathrm{Fe}_{3} \mathrm{O}_{4} \text { nanoparticles based visible } \\
\text { detection }\end{array}$ & $3.58 \times 10^{3}$ & 20 \\
\hline Concentration normalized electroanalytical assaying & 190 & 21 \\
\hline Electrochemical detection using DNA nanotetrahedra & 20.90 & 22 \\
\hline Quantum dot-based electrochemical detection & 100 & 23 \\
\hline $\begin{array}{l}\text { Cyclic enzymatic amplification-based electrochemical } \\
\text { detection }\end{array}$ & 70 & 24 \\
\hline $\begin{array}{c}\text { Gold-loaded nanoporous ferric oxide nanozymes based } \\
\text { electrochemical detection }\end{array}$ & 1 & 25 \\
\hline $\begin{array}{c}\text { An ultrasensitive electrochemical aptasensor based on click } \\
\text { chemistry }\end{array}$ & 96 & 26 \\
\hline $\begin{array}{l}\text { A catalytic molecule machine-driven biosensing method } \\
\text { for amplified electrochemical detection of exosomes }\end{array}$ & 17.20 & 27 \\
\hline The commercial kit (ExoELISA-ULTRA CD63 kit) & $7.91 \times 10^{7 *}$ & $\begin{array}{r}\text { This } \\
\text { work }\end{array}$ \\
\hline $\begin{array}{l}\text { Multi-legged exosomal walker-based electrochemical } \\
\text { detection }\end{array}$ & 29 & $\begin{array}{r}\text { This } \\
\text { work }\end{array}$ \\
\hline
\end{tabular}

* The LOD of commercial kit was calculated based on the $3 \sigma$ rule, where the $3 \sigma(\sigma=0.0217)$ was regarded as $\Delta \mathrm{A}$ and then put into the regression equation $(\Delta \mathrm{A}=0.1011 \mathrm{C}+0.0643)$ in Figure $\mathrm{S} 1$ for 
the calculation of $\mathrm{C}$ (C was the $\mathrm{LOD})$.

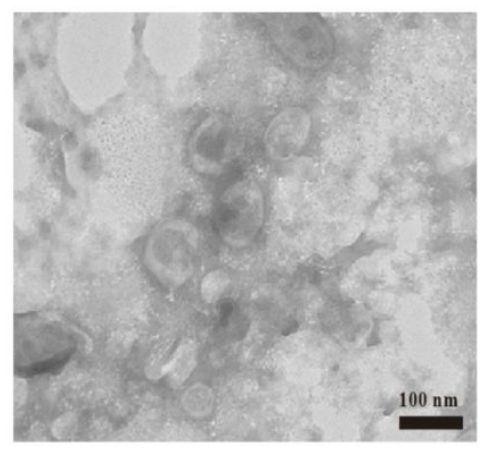

A

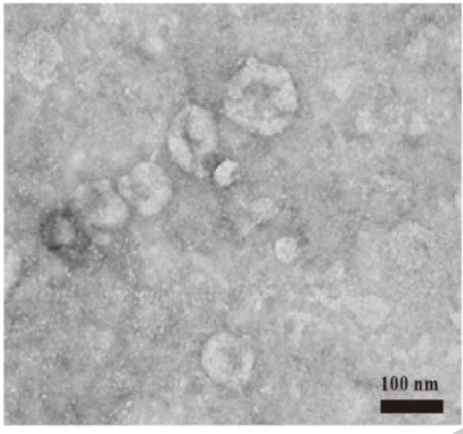

B

Figure S11. The transmission electron microscope (TEM) images of MCF-7 cells (A) and MCF-10A cells (B) derived exosomes isolated by ultracentrifugation. The TEM images of MCF-7 cells and MCF-10A cells derived exosomes both displayed "cup" or "saucer" like morphology of exosomes with a diameter range of $70-100 \mathrm{~nm}$.
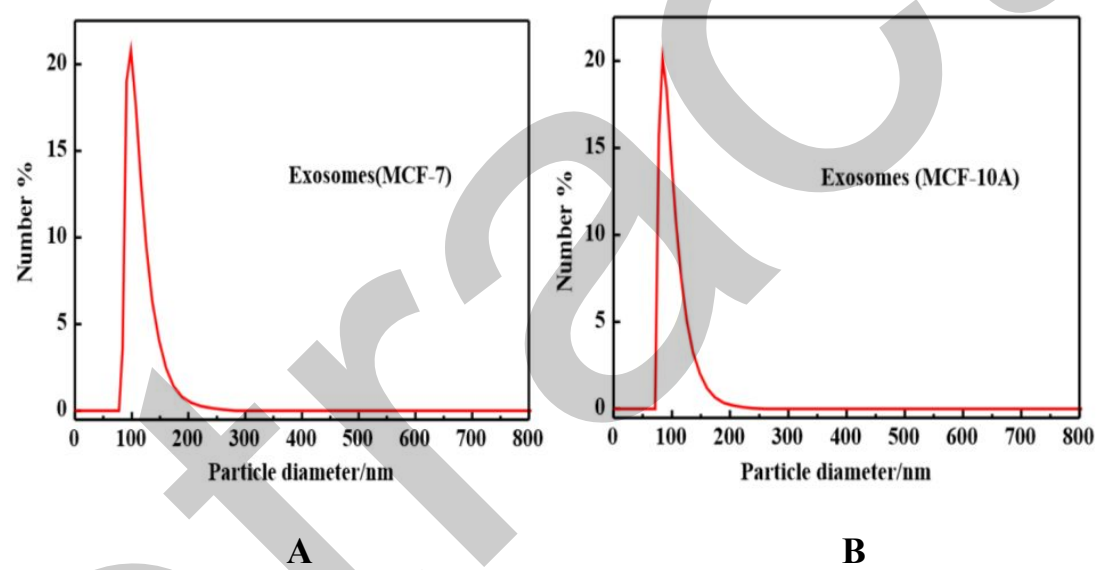

Figure S12. The dynamic light scattering (DLS) measurements of MCF-7 cells (A) and MCF-10A cells (B) derived exosomes isolated by ultracentrifugation. The MCF-7 cells derived exosomes had mean effective diameter of $117 \pm 4.3 \mathrm{~nm}$ with a polydispersity index (PDI) of 0.16 , and the MCF-10A cells derived exosomes possesses a mean effective diameter of $102 \pm 2.4 \mathrm{~nm}$ with a PDI of 0.15 . 
Table S6. The repeated detection of exosomes for 5 times

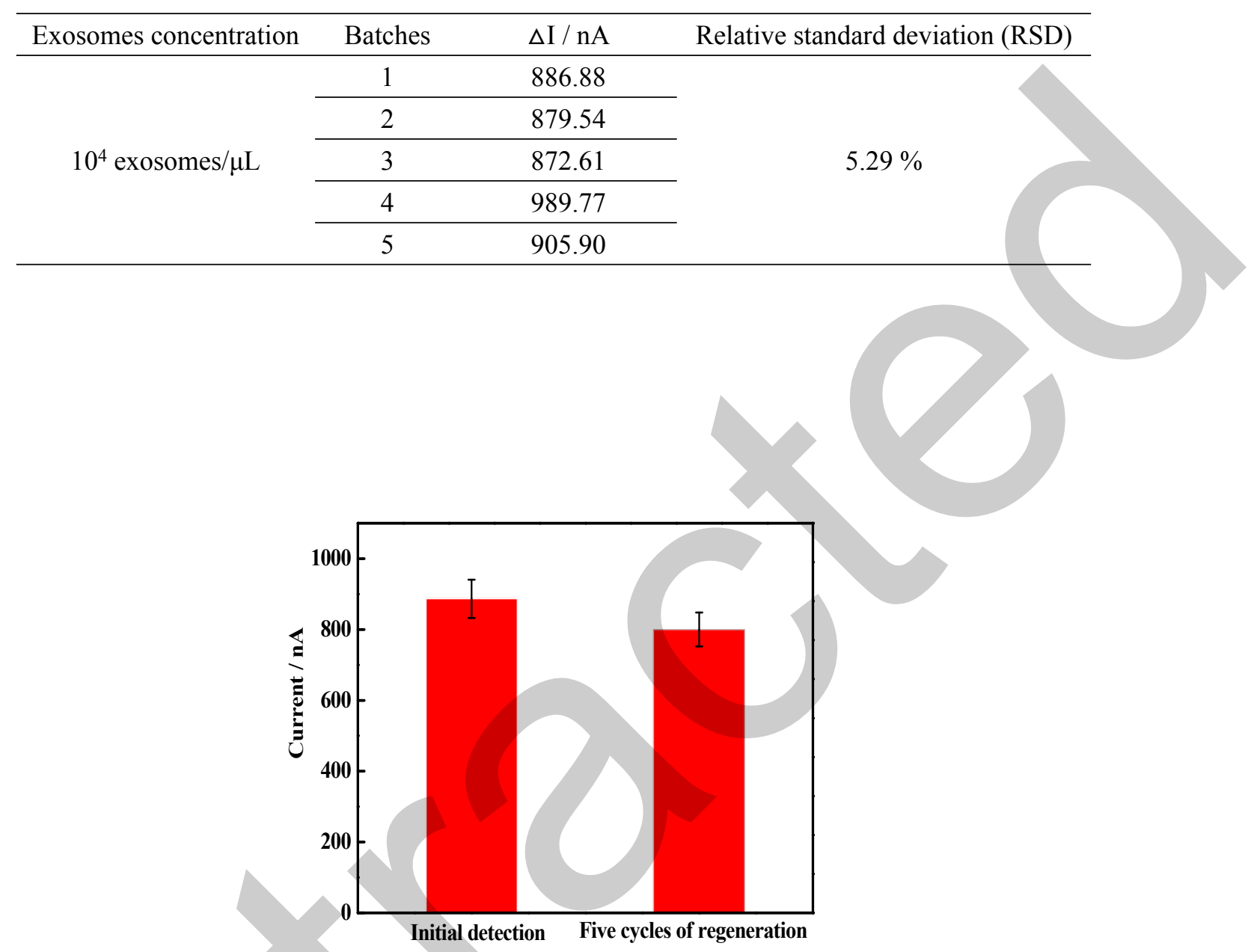

Figure S13. The current intensity of initial detection and after the 5 cycles of the regeneration procedure. 


\section{REFERENCES}

(1) Labib, M.; Green, B.; Mohamadi, R. M.; Mepham, A.; Ahmed, S. U.; Mahmoudian, L.; Chang, I. H.; Sargent, E. H.; Kelley, S. O. Aptamer and antisense-mediated two-dimensional isolation of specific cancer cell subpopulations. J. Am. Chem. Soc. 2016, 138, 2476-2479.

(2) Tomov, T. E.; Tsukanov, R.; Liber, M.; Masoud, R.; Plavner, N.; Nir, E. Rational design of DNA motors: fuel optimization through single-molecule fluorescence. J. Am. Chem. Soc. 2013, 135, 11935-11941.

(3) Liber, M.; Tomov, T. E.; Tsukanov, R.; Berger, Y.; Nir, E. A bipedal DNA motor that travels back and forth between two DNA origami tiles. Small. 2015, 11, 568-575.

(4) Gu, H.; Chao, J.; Xiao, S. J.; Seeman, N. C. A proximity-based programmable DNA nanoscale assembly line. Nature. 2010, 465, 202-205.

(5) Jung, C.; Allen, P. B.; Ellington, A. D. A stochastic DNA walker that traverses a microparticle surface. Nat. Nanotechnol. 2016, 11, 157-163.

(6) Jung, C.; Allen, P. B.; Ellington, A. D. A simple, cleated DNA walker that hangs on to surfaces. ACS Nano. 2017, 11, 8047-8054.

(7) Demers, L. M.; Mirkin, C. A.; Mucic, R. C.; Reynolds, R. A.; Letsinger, R. L.; Elghanian, R.; Viswanadham, G. A fluorescence-based method for determining the surface coverage and hybridization efficiency of thiol-capped oligonucleotides bound to gold thin films and nanoparticles. Anal. Chem. 2000, 72, 5535-5541.

(8) Tian, Y. F.; Ning, C. F.; He, F.; Yin, B. C.; Ye, B. C. Highly sensitive detection of exosomes by SERS using gold nanostar@Raman reporter@nanoshell structures modified with a bivalent cholesterol-labeled DNA anchor. Analyst. 2018, 143, 4915-4922.

(9) Li, T. D.; Zhang, R.; Chen, H.; Huang, Z. P.; Ye, X.; Wang, H.; Deng, A. M.; Kong, J. L. An ultrasensitive polydopamine bi-functionalized SERS immunoassay for exosome-based diagnosis and classification of pancreatic cancer. Chem. Sci. 2018, 9, 5372-5382.

(10) Wang, Q.; Zou, L.; Yang, X.; Liu, X.; Nie, W.; Zheng, Y.; Cheng, Q.; Wang, K. Direct quantification of cancerous exosomes via surface plasmon resonance with dual gold nanoparticle-assisted signal amplification. Biosens. Bioelectron. 2019, 135, 129-136.

(11) Liu, C.; Xu, X.; Li, B.; Situ, B.; Pan, W.; Hu, Y.; An, T.; Yao, S.; Zheng, L. Single-exosome-counting immunoassays for cancer diagnostics. Nano Lett. 2018, 18, 4226-4232.

(12) Xu, H.; Liao, C.; Zuo, P.; Liu, Z.; Ye, B. C. Magnetic-based microfluidic device for on-chip isolation and detection of tumor-derived exosomes. Anal. Chem. 2018, 90, 13451-13458.

(13) Huang, L.; Wang, D. B.; Singh, N.; Yang, F.; Gu, N.; Zhang, X. E. A dual-signal amplification platform for sensitive fluorescence biosensing of leukemia-derived exosomes. Nanoscale. 2018, 10, 20289-20295.

(14) Zhang, Q.; Wang, F.; Zhang, H.; Zhang, Y.; Liu, M.; Liu, Y. Universal $\mathrm{Ti}_{3} \mathrm{C}_{2}$ MXenes based self-standard ratiometric fluorescence resonance energy transfer platform for highly sensitive detection of exosomes. Anal. Chem. 2018, 90, 12737-12744.

(15) Jin, D.; Yang, F.; Zhang, Y.; Liu, L.; Zhou, Y.; Wang, F.; Zhang G. J. ExoAPP: exosome-oriented, aptamer nanoprobe-enabled surface proteins profiling and detection. Anal. Chem. 2018, 90, 14402-14411.

(16) He, D.; Ho, S. L.; Chan, H. N.; Wang, H.; Hai, L.; He, X.; Wang, K.; Li, H. W. Molecular-recognition-based DNA nanodevices for enhancing the direct visualization and quantification of single vesicles of tumor exosomes in plasma microsamples. Anal. Chem. 2019, 91, 2768-2775.

(17) Gao, M. L.; He, F.; Yin, B. C.; Ye, B. C. A dual signal amplification method for exosome detection based on DNA dendrimer self-assembly. Analyst. 2019, 144, 1995-2002.

(18) Wang, L.; Yang, Y.; Liu, Y.; Ning, L.; Xiang, Y.; Li, G. Bridging exosome and liposome through S-18 
zirconium-phosphate coordination chemistry: a new method for exosome detection. Chem. Commun. 2019, 55, 2708-2711.

(19) Zhang, H.; Wang, Z.; Zhang, Q.; Wang, F.; Liu, Y. $\mathrm{Ti}_{3} \mathrm{C}_{2}$ MXenes nanosheets catalyzed highly efficient electrogenerated chemiluminescence biosensor for the detection of exosomes. Biosens. Bioelectron. 2019, 124-125, 184-190.

(20) Chen, J.; Xu, Y.; Lu, Y.; Xing, W. Isolation and visible detection of tumor-derived exosomes from plasma. Anal. Chem. 2018, 90, 14207-14215.

(21) Li, Q.; Tofaris, G. K.; Davis, J. J. Concentration-normalized electroanalytical assaying of exosomal markers. Anal. Chem. 2017, 89, 3184-3190.

(22) Wang, S.; Zhang, L.; Wan, S.; Cansiz, S.; Cui, C.; Liu, Y.; Cai, R.; Hong, C.; Teng, I. T.; Shi, M.; Wu, Y.; Dong, Y.; Tan, W. Aptasensor with expanded nucleotide using DNA nanotetrahedra for electrochemical detection of cancerous exosomes. ACS Nano. 2017, 11, 3943-3949.

(23) Boriachek, K.; Islam, M. N.; Gopalan, V.; Lam, A. K.; Nguyen, N. T.; Shiddiky, M. J. A. Quantum dot-based sensitive detection of disease specific exosome in serum. Analyst. 2017, 142, 2211-2219.

(24) Dong, H.; Chen, H.; Jiang, J.; Zhang, H.; Cai, C.; Shen, Q. Highly sensitive electrochemical detection of tumor exosomes based on aptamer recognition-induced multi-DNA release and cyclic enzymatic amplification. Anal. Chem. 2018, 90, 4507-4513.

(25) Boriachek, K.; Masud, M. K.; Palma, C.; Phan, H. P.; Yamauchi, Y.; Hossain, M. S. A.; Nguyen, N. T.; Salomon, C.; Shiddiky, M. J. A. Avoiding pre-isolation step in exosome analysis: direct isolation and sensitive detection of exosomes using gold-loaded nanoporous ferric oxide nanozymes. Anal. Chem. 2019, 91, 3827-3834.

(26) An, Y.; Jin, T.; Zhu, Y.; Zhang, F.; He, P. An ultrasensitive electrochemical aptasensor for the determination of tumor exosomes based on click chemistry. Biosens. Bioelectron. 2019, 142, 111503.

(27) Cao, Y.; Li, L.; Han, B.; Wang, Y.; Dai, Y.; Zhao, J. A catalytic molecule machine-driven biosensing method for amplified electrochemical detection of exosomes. Biosens. Bioelectron. 2019, 141, 111397. 